\title{
Vascular Endothelial Growth Factor Receptor Type 1 Signaling Prevents Delayed Wound Healing in Diabetes by Attenuating the Production of IL-1 $\beta$ by Recruited Macrophages
}

Shin-ichiro Okizaki, ${ }^{\dagger \dagger}$ Yoshiya Ito, ${ }^{\ddagger}$ Kanako Hosono, ${ }^{*}$ Kazuhito Oba, ${ }^{* \dagger}$ Hirotoki Ohkubo, ${ }^{\ddagger}$ Ken Kojo, ${ }^{*}$ Nobuyuki Nishizawa, ${ }^{*}$ Masabumi Shibuya, ${ }^{\S}$ Masayoshi Shichiri, ${ }^{\dagger}$ and Masataka Majima*

From the Departments of Pharmacology, ${ }^{*}$ Endocrinology, ${ }^{\dagger}$ and Surgery, ${ }^{\ddagger}$ Kitasato University School of Medicine, Kanagawa; and the Institute of Physiology and Medicine, ${ }^{\S}$ Jobu University, Gunma, Japan

\author{
Accepted for publication \\ February 1, 2016. \\ Address correspondence to \\ Masataka Majima, M.D., Ph.D., \\ Department of Pharmacology, \\ Kitasato University School of \\ Medicine, 1-15-1 Kitasato, \\ Minami-ku, Sagamihara, \\ Kanagawa, 252-0374, \\ Japan. E-mail: mmajima@ \\ med.kitasato-u.ac.jp.
}

\begin{abstract}
The persistence of proinflammatory macrophages, which are recruited to the granulation tissue, impairs the healing of diabetic wounds. Herein, we examined the role of vascular endothelial growth factor receptor type 1 (VEGFR1) signaling in streptozotocin (STZ)-induced diabetic wound healing. Angiogenesis, lymphangiogenesis, and the healing of full-thickness skin wounds were impaired in STZ-treated wild-type (WT) mice compared with vehicle-treated WT mice, with attenuated recruitment of VEGFR1-positive macrophages expressing vascular endothelial growth factor (VEGF)-A, VEGF-C, and VEGF-D to the wound granulation tissue. These phenomena were even more prevalent in STZ-treated VEGFR1 tyrosine kinase knockout mice (VEGFR1 TK ${ }^{-1-}$ mice). STZ-treated WT mice, but not STZ-treated VEGFR1 TK ${ }^{-1-}$ mice, showed accelerated wound healing when treated with placenta growth factor. Compared with that of STZ-treated WT mice, the wound granulation tissue of STZ-treated VEGFR1 TK ${ }^{-/-}$mice contained more VEGFR1-positive cells expressing IL-1 $\beta$ [a classic (M1) activated macrophage marker] and fewer VEGFR1positive cells expressing the mannose receptor [CD206; an alternatively activated (M2) macrophage marker]. Treatment of STZ-treated VEGFR1 TK ${ }^{-/-}$mice with an IL-1 $\beta$-neutralizing antibody restored impaired wound healing and angiogenesis/lymphangiogenesis and induced macrophages in the wound granulation tissue to switch to an M2 phenotype. Taken together, these results suggest that VEGFR1 signaling plays a role in regulating the balance between macrophage phenotypes in STZ-induced diabetic wounds, prevents impaired diabetic wound healing, and promotes angiogenesis/lymphangiogenesis. (Am J Pathol 2016, 186: 1481-1498; http://dx.doi.org/10.1016/j.ajpath.2016.02.014)
\end{abstract}

Diabetic wounds are among the most severe type of chronic wound. Such wounds reduce the quality of life of millions of patients with diabetes mellitus..$^{1}$ Impaired wound healing is a common complication associated with diabetes, and is linked to inadequate angiogenesis and lymphangiogenesis, leading to chronic diabetic ulcers. ${ }^{2}$

The innate immune response of resident cells and recruited inflammatory cells plays a critical role in wound healing. ${ }^{3}$ Macrophages are a major component of wound granulation tissue and play a prominent role in healing and angiogenesis/lymphangiogenesis. ${ }^{4-6}$ Inhibiting macrophage recruitment suppresses both angiogenesis and lymphangiogenesis in mice with suture-induced inflammatory corneal neovascularization. ${ }^{7,8}$ Also, macrophage depletion attenuates inflammation-induced lymphangiogenesis. ${ }^{9}$ Reduced numbers of macrophages and insufficient macrophage activation contribute to the impaired healing of diabetic wounds. ${ }^{10}$ Macrophage recruitment is

Supported by The Ministry of Education, Culture, Sports, Science and Technology grants 25462100 (Y.I.), 15K15056, 80532556, 23116102, 24659119, 26462132, and 26293055, Takeda Science Foundation, and Uehara Memorial Foundation (M.M.).

Disclosures: None declared. 
essential for diabetic wound repair because they release important mediators within the wound. ${ }^{2,11,12}$ Furthermore, wound macrophages undergo dynamic changes during different phases of wound healing. During the early stages of productive wound healing, M1-polarized macrophages initiate and sustain the inflammatory response, whereas M2-polarized macrophages are involved in tissue repair and regeneration during the later stages. ${ }^{13,14}$ During the healing process, diabetic wounds exhibit prolonged accumulation of macrophages, which are associated with increased levels of proinflammatory cytokines and reduced levels of various growth factors. ${ }^{15}$ Persistent macrophagedriven inflammation is one of the primary pathologies associated with diabetic wounds. ${ }^{2,16}$

Vascular endothelial growth factor (VEGF)-A is a major regulator of both vascular development and physiological and pathological angiogenesis during tumorigenesis, inflammation, and wound healing. ${ }^{17,18}$ The biological activity of VEGF-A is dependent on its interaction with specific receptors. VEGF-A acts primarily through two tyrosine kinase (TK) receptors: VEGF receptor 1 (VEGFR1) and VEGF receptor 2 (VEGFR2). ${ }^{17,18}$ VEGF-A-induced angiogenesis is mediated primarily by VEGFR2, whereas VEGFR1 signaling contributes to pathological angiogenesis under certain conditions. ${ }^{19-22}$ VEGFR1 is expressed not only on endothelial cells (ECs), ${ }^{17,18}$ but also by monocytes/ macrophages, ${ }^{23,24}$ and is important for VEGF-A-dependent migration. ${ }^{19}$ Previously, we suggested that VEGFR1 signaling mediates monocyte/macrophage infiltration at local inflammatory sites, and that VEGFR1 signaling promotes the recruitment of VEGFR1-expressing macrophages to repair inflamed tissues. ${ }^{2,25,26}$ We also reported that VEGFR1 signaling plays an essential role in nondiabetic wound-induced angiogenesis and lymphangiogenesis by recruiting macrophages. ${ }^{27}$ Gene transfer of placenta growth factor (PIGF), a specific agonist for VEGFR1, into streptozotocin (STZ)induced diabetic mice accelerates wound closure and increases recruitment of monocytes/macrophages to the wound granulation tissue. ${ }^{28}$ Although these findings suggest that overexpression of VEGFR1 would promote diabetic wound healing via macrophage recruitment, the mechanisms by which endogenous VEGFR1 signaling affects diabetic wound healing and angiogenesis/lymphangiogenesis remain unknown.

Our aim was to examine whether VEGFR1 signaling in macrophages plays an important role in diabetic wound healing. We also examined the mechanisms by which VEGFR1 signaling affects wound healing in diabetic subjects. We found that deficiencies in VEGFR1 signaling mediated delayed STZ-induced diabetic wound healing and angiogenesis/lymphangiogenesis, and suppressed recruitment of VEGFR1-positive macrophages to the granulation tissue. Deficient VEGFR1 signaling prevented adequate polarization of VEGFR1-positive macrophages in STZ-induced diabetic wounds, resulting in up-regulated expression of proinflammatory mediators, such as IL- $1 \beta$. We also found that treatment of STZ-treated VEGFR1 TK knockout mice with a neutralizing antibody against IL- $1 \beta$ restored impaired wound healing and angiogenesis/lymphangiogenesis by inducing the recruitment of M2-polarized VEGFR1-positive macrophages. Taken together, these results suggest that VEGFR1-mediated signaling inhibits IL-1 $\beta$ production by macrophages, and is important for the recruitment of VEGFR1-expressing macrophages to STZ-induced diabetic wounds.

\section{Materials and Methods}

\section{Animals}

Male C57B1/6 mice ( 8 weeks old) were obtained from CLEA Japan (Tokyo, Japan). VEGFR1 tyrosine kinase knockout mice (VEGFR1 TK ${ }^{-1-}$ mice; 8 weeks old) with a C57BL/6 hybrid background were generated in-house. ${ }^{19}$ Mice were maintained at constant humidity $(60 \% \pm 5 \%)$ and temperature $\left(25^{\circ} \mathrm{C} \pm 1{ }^{\circ} \mathrm{C}\right)$ on a 12-hour light/dark cycle. All animals were provided with food and water ad libitum. All experimental procedures were approved by the Animal Experimentation and Ethics Committee of the Kitasato University School of Medicine (Kanagawa, Japan), and were performed in accordance with the guidelines for animal experiments set down by the Kitasato University School of Medicine.

\section{Animal Model of Diabetes}

Diabetes was induced in 8-week-old mice by a single i.p. injection of $100 \mathrm{mg} / \mathrm{kg}$ streptozotocin (STZ; Sigma-Aldrich,

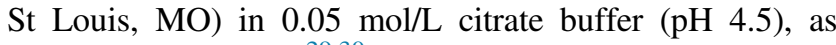
described previously. ${ }^{29,30}$ Vehicle (citrate buffer)-injected animals served as controls. Blood glucose levels were measured with a portable glucometer (GR-102; Terumo, Tokyo, Japan) 4 weeks after treatment with STZ to confirm successful induction of diabetes. Animals with blood glucose levels $>400 \mathrm{mg} / \mathrm{dL}$ were considered diabetic and used for subsequent experiments.

\section{Dorsal Excisional Wound Model}

Surgical wounds were made on the backs of the mice, as previously described. ${ }^{5,6,30}$ Briefly, mice were i.p. anesthetized with $50 \mathrm{mg} / \mathrm{kg}$ pentobarbital sodium, the dorsal hair was shaved, the skin was cleaned with $70 \%$ ethanol, and full-thickness excisional skin wounds $(6 \mathrm{~mm}$ in diameter) were made aseptically on either side of the dorsal midline using a biopsy punch (Kai Industries, Tokyo, Japan). Dorsal wounds were monitored macroscopically by taking digital photographs at the indicated times. The wound area was calculated from the photographs using ImageJ analysis software version 1.48 (NIH, Bethesda, MD; http://imagej. nih.gov/ij) and expressed as a percentage of the original wound area. 
Treatment with a Neutralizing Antibody against IL-1 $\beta$

In another set of experiments, STZ-treated mice received a neutralizing antibody against IL- $1 \beta[1 \mu \mathrm{g} /$ mouse per day in $100 \mu \mathrm{L}$ of phosphate-buffered saline (PBS)] (R\&D Systems, Minneapolis, MN) or vehicle (rat IgG) ${ }^{31}$ for 7 days, starting on the day of wounding. The anti-IL-1 $\beta$ antibody and vehicle were delivered via Alzet osmotic pumps (model 1007D; Palo Alto, CA) implanted s.c. at the time of surgical wounding.

\section{Treatment with PLGF}

In another set of experiments, STZ-treated mice received recombinant human PIGF in $100 \mu \mathrm{L}$ of PBS $(10 \mu \mathrm{g} /$ mouse for 7 consecutive days) (BioLegend, San Diego, CA) or vehicle (human $\operatorname{IgG}$ ), ${ }^{32,33}$ starting on the day of wounding. PIGF or vehicle was delivered via Alzet osmotic pumps (model 1007D) implanted s.c. at the time of surgical wounding.

\section{Histology}

Excised wound tissues were fixed immediately with $4 \%$ paraformaldehyde in $0.1 \mathrm{~mol} / \mathrm{L}$ sodium phosphate buffer (pH 7.4) for histological analysis. ${ }^{6,22}$ Sections (4 $\mu \mathrm{m}$ thick) were prepared from paraffin-embedded tissue and subjected to hematoxylin and eosin staining. Images of hematoxylin and eosin-stained sections were captured under a fluorescence microscope (Biozero BZ-9000 Series; Keyence, Osaka, Japan). The length of epithelial tongue, distance of epithelial tips, and the area of the wound granulation tissue were measured using ImageJ software.

\section{Immunofluorescence Analysis}

Tissue samples were fixed with $4 \%$ paraformaldehyde in 0.1 $\mathrm{mol} / \mathrm{L}$ sodium phosphate buffer $(\mathrm{pH} 7.4)$ at $4^{\circ} \mathrm{C}$ for 4 hours. ${ }^{6,22}$ After cryoprotection with $30 \%$ sucrose $/ 0.1 \mathrm{~mol} / \mathrm{L}$ phosphate buffer ( $\mathrm{pH} 7.2$ ), sections (approximately $8 \mu \mathrm{m}$ thick) were cut using a cryostat. Sections were then incubated with $1 \%$ bovine serum albumin/PBS at room temperature for 1 hour to block non-specific binding, followed by incubation with a rat anti-mouse F4/80 monoclonal IgG2a antibody (Santa Cruz Biotechnology Inc., Dallas, TX), a rabbit or goat anti-mouse VEGFR1 polyclonal IgG antibody (Santa Cruz Biotechnology Inc.), a rabbit antimouse lymphatic vessel endothelial hyaluronan receptor (Lyve-1) antibody (Abcam, Cambridge, MA), an anti-CD31 rabbit polyclonal antibody (Abcam), a goat anti-mouse podoplanin polyclonal antibody (R\&D Systems), a rat anti-mouse MECA-32 polyclonal antibody (AbD Serotec, Raleigh, NC), a goat anti-desmin polyclonal antibody (Abcam), a rat anti-mouse Gr-1 monoclonal IgG2b antibody (AbD Serotec), a rat anti-mouse mannose receptor (MR) (CD206) monoclonal IgG antibody (AbD Serotec), a rat anti-mouse IL-1 $\beta$ antibody (R\&D Systems), a goat antimouse VEGF-A polyclonal IgG antibody (Santa Cruz
Biotechnology Inc.), a goat anti-mouse VEGF-C polyclonal IgG antibody (Santa Cruz Biotechnology Inc.), or a goat anti-mouse VEGF-D polyclonal IgG antibody (Santa Cruz Biotechnology Inc.). After washing three times in PBS, the sections were incubated with the following secondary antibodies for 1 hour at room temperature: Alexa Fluor 488-conjugated donkey anti-rabbit IgG, Alexa Fluor 594-conjugated donkey anti-rat IgG, and/or Alexa Fluor 594-conjugated donkey anti-goat IgG. Images were captured under a fluorescence microscope (Biozero BZ-9000 Series; Keyence). After labeling, five fields (magnification, $\times 200$ ) within the wound granulation tissue were selected, and the number of positive cells was counted. The results were expressed as the average number of positive cells per field. Wound-induced angiogenesis and lymphangiogenesis in the granulation tissue were estimated according to microvessel density using established methods, ${ }^{6,30}$ and the results were expressed as the number of vessels per square millimeter.

\section{Flow Cytometry}

Wound granulation tissues were harvested and dissected into small pieces by a microscissor, and the pieces were incubated with Dulbecco's minimum essential medium containing 1\% collagenase D (Roche Diagnostic Corp., Indianapolis, IN) and $1000 \mathrm{pU} / \mathrm{mL}$ dispase for 1 hour at $37^{\circ} \mathrm{C}$. After inactivation of collagenase activity, the cell suspension was filtered through a $70-\mu \mathrm{m}$ nylon filter (BD Biosciences, San Jose, CA), centrifuged at $1200 \times g$ for 5 minutes, and washed with PBS containing $0.5 \%$ bovine serum albumin. The cells were labeled with phycoerythrinlabeled anti-VEGFR1 (R\&D Systems) and fluorescein isothiocyanate-conjugated F4/80 (eBioscience, San Diego, CA). After washing, the cells were analyzed by flow cytometry (FACSCalibur; BD Biosciences), as previously described. $^{22}$ The data were analyzed using the Kaluza software version 1.3 (Beckman Coulter, Brea, CA).

\section{Real-Time RT-PCR}

Transcripts encoding CD31, VEGF-A, VEGF-C, VEGF-D, VEGFR1, VEGFR2, VEGFR3, Lyve-1, F4/80, IL-1 $\beta$, tumor necrosis factor- $\alpha$, MR, arginase $1, \mathrm{C}-\mathrm{C}$ motif chemokine 2 (CCL2), C-C chemokine receptor type 2 (CCR2), and glyceraldehyde-3-phosphate dehydrogenase were examined by real-time RT-PCR. Briefly, total RNA was extracted from wound granulation tissue, but not epidermis, and homogenized in TRIzol reagent (Gibco-BRL/Life Technologies, Grand Island, NY). Single-stranded cDNA was generated from $1 \mu \mathrm{g}$ of total RNA by reverse transcription using ReverTra Ace (Toyobo, Osaka, Japan), according to the manufacturer's instructions. Quantitative PCR amplification was performed with SYBR Premix Ex Taq (Takara, Shiga, Japan). The gene-specific primers are listed in Table 1. Data were normalized to the level of glyceraldehyde-3-phosphate dehydrogenase in each sample. 
Table 1 The Primers Used for Reverse Transcription and Quantitative PCR Reactions

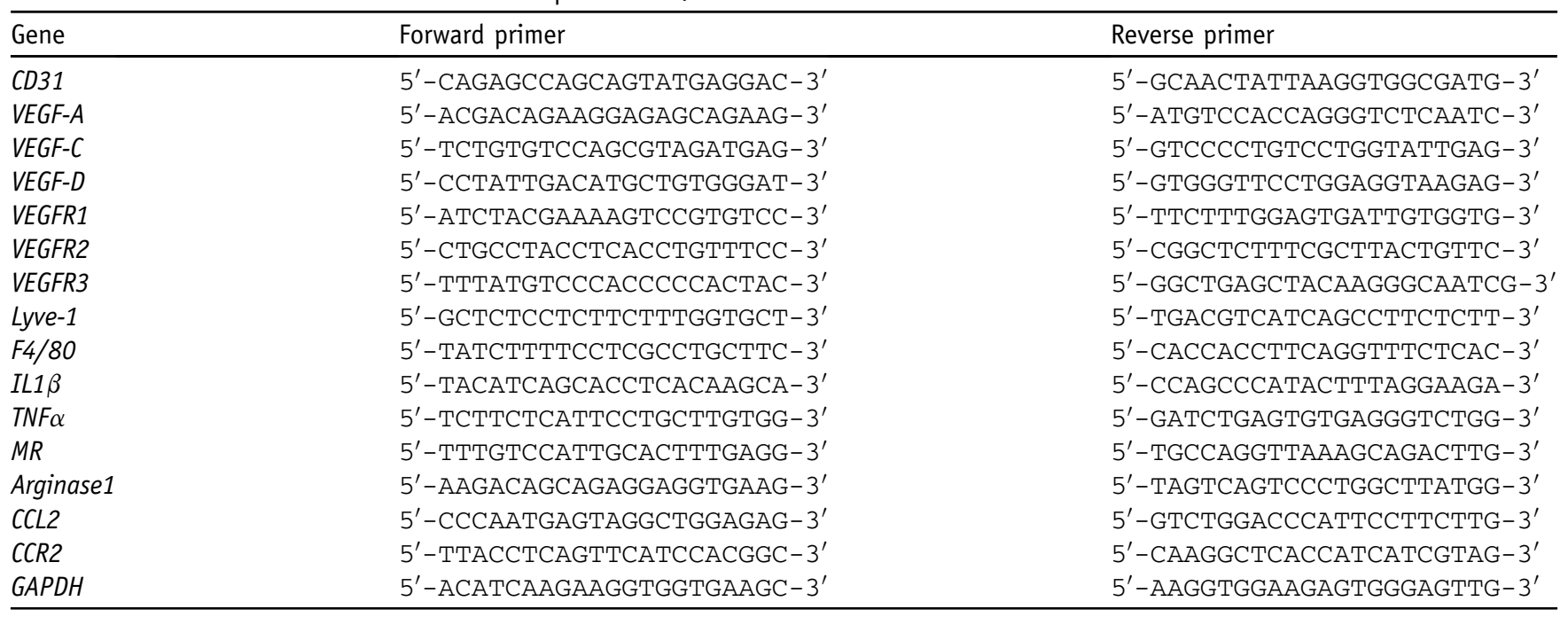

\section{Cell Culture}

Peritoneal macrophages were induced in wild-type (WT) mice and VEGFR1 $\mathrm{TK}^{-1-}$ mice using thioglycollate. ${ }^{22,34}$ Three days after i.p. injection of $2 \mathrm{~mL}$ of $4 \%$ thioglycollate medium (Nissui Pharmaceutical Co Ltd, Tokyo, Japan), induced macrophages were obtained via peritoneal lavage twice with $5 \mathrm{~mL}$ of PBS. Peritoneal exudate cells were washed and suspended in RPMI 1640 medium (Cambrex, Baltimore, MD) containing $10 \%$ fetal bovine serum and added to 6-well tissue culture plates $\left(2 \times 10^{6}\right.$ cells per well). The macrophages were cultured for 24 hours at $37^{\circ} \mathrm{C}$ in $5 \%$ humidified $\mathrm{CO}_{2}$. After 24 hours, the plates were washed with PBS to remove nonadherent cells. The resulting peritoneal macrophages were plated in 6-well tissue culture plates $\left(3 \times 10^{5}\right.$ cells per well $)$ and stimulated with recombinant murine PlGF (BioVision, Inc., Milpitas, CA) for 6 hours. Total RNA was extracted from these cultured cells using TRIzol (Invitrogen, Carlsbad, CA), and the relative expression of VEGF-A, VEGF-C, VEGF-D, VEGFR1, IL-1 $\beta$, and MR was determined.

\section{Cell Proliferation Assay}

Human lymphatic microvascular endothelial cells (HMVECdLyNeo: CC-2812) were obtained from Takara and cultured in EGMs-2-MV BulletKitDMEM supplemented with 5\% (v/v) fetal bovine serum at $37^{\circ} \mathrm{C}$ in $5 \%$ humidified $\mathrm{CO}_{2}$ in the presence of $100 \mathrm{U} / \mathrm{mL}$ penicillin and $100 \mathrm{mg} / \mathrm{mL}$ of streptomycin, as described previously. ${ }^{35}$ HMVEC-dLyNeo (in 6-well tissue culture plates; $3 \times 10^{5}$ cells per well) were stimulated with human recombinant PlGF (BioVision, Inc.) or human recombinant VEGF-C (R\&D Systems) for 24 hours before the addition of PremixWST-1 (Takara Bio Inc., Otsu, Japan). After 4 hours of incubation, absorbance $(450 \mathrm{~nm} / 650 \mathrm{~nm})$ was measured in a SoftMax Pro Multi Plate Reader (Molecular Devices, Sunnyvale, CA) as a marker of cell proliferation.

\section{BM Transplantation}

For the bone marrow (BM) transplantation experiments, transgenic mice expressing green fluorescent protein (GFP) against a C57BL/6 background were used to confirm BM chimerism. VEGFR1 $\mathrm{TK}^{-/-}$mice and $\mathrm{GFP}^{+/+}$mice were crossed to obtain GFP + VEGFR1 $\mathrm{TK}^{-1-}$ mice. $^{22,26} \mathrm{BM}$ transplantation was performed as previously described. ${ }^{22,26}$ Briefly, donor BM cells from GFP + VEGFR1 $\mathrm{TK}^{-/-}$ mice or their GFP + WT counterparts were harvested using the same method. ${ }^{22,26}$ Donor BM-derived mononuclear cells $\left(2 \times 10^{6}\right.$ cells $\left./ 200 \mu \mathrm{L} \mathrm{PBS}\right)$ were injected into the tail vein of irradiated WT mice. After 8 weeks, peripheral blood was collected and GFP expression was analyzed by fluorescenceactivated cell sorting to assess BM chimerism. Mice in which $>90 \%$ of the peripheral leukocytes were donor marker positive were used for subsequent experiments.

\section{Statistical Analysis}

All results are expressed as the means \pm SEM. All statistical analyses were performed using GraphPad Prism software version 6.01 (GraphPad Software, La Jolla, CA). A $t$-test was used to compare data between two groups, and one-way analysis of variance, followed by Bonferroni's post hoc test was used to compare data between multiple groups. $P<0.05$ was considered statistically significant.

\section{Results}

Delayed Wound Healing and Impaired Angiogenesis in STZ-Induced Diabetic VEGFR1 $\mathrm{TK}^{-/-}$Mice

Full-thickness incisional wounds were surgically generated on the backs of mice (Supplemental Figure S1), and wound closure was monitored (Figure 1A). The healing process in STZ-induced diabetic WT mice was slower than that in 
A

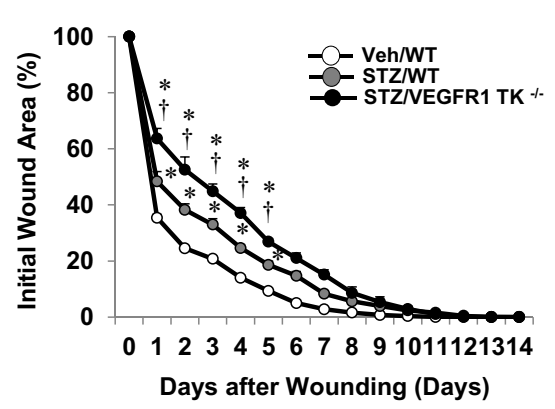

C

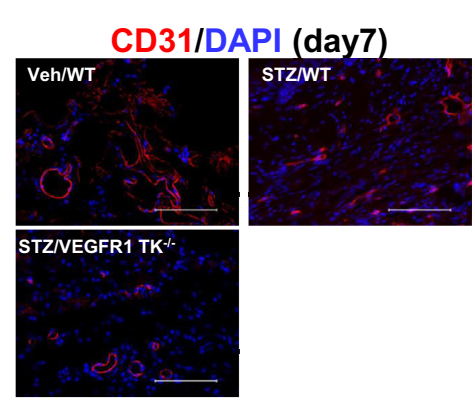

B
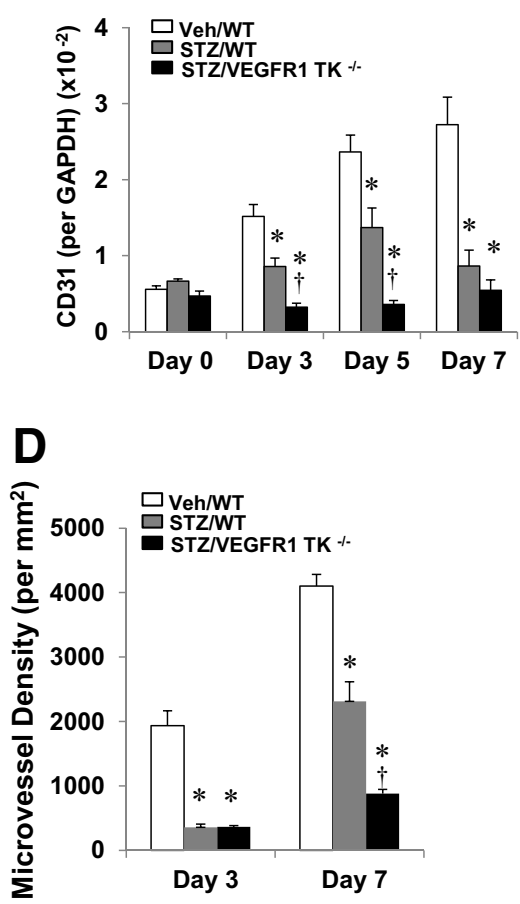

$\mathbf{F}$

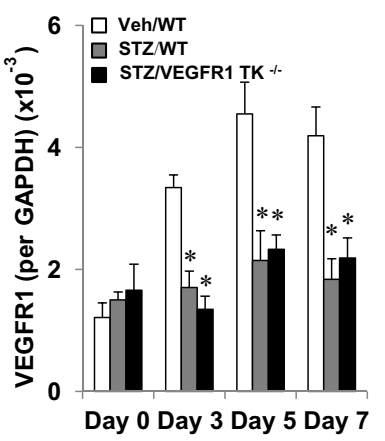

G

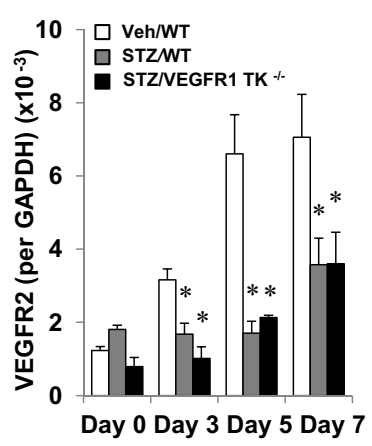

Figure 1 Vascular endothelial growth factor receptor type 1 (VEGFR1) signaling accelerates streptozotocin (STZ)-induced diabetic wound healing and angiogenesis in mice. A: Time course of wound closure in wild-type (WT) mice treated with vehicle (Veh) or STZ, and of VEGFR1 tyrosine kinase $(\mathrm{TK})^{-/-}$mice treated with STZ. The original diameter of the wounds was $6 \mathrm{~mm}$. B: Changes in the expression of CD31 mRNA in wound granulation tissue. C: Typical appearance of wound granulation tissue from WT mice treated with Veh or STZ, and from VEGFR1 $\mathrm{TK}^{-/-}$mice treated with STZ, at day 3 after wounding. Tissues were stained for CD31 (red). Cell nuclei were stained with DAPI (blue). D: Microvessel density in wound granulation tissue from WT mice treated with Veh or STZ, and from VEGFR1 TK ${ }^{-/}$mice treated with STZ, at days 3 and 7. $\mathbf{E}-\mathbf{G}$ : Changes in the expression of VEGF-A and its receptors in the wound granulation tissue. The levels of VEGF-A (E), VEGFR1 (F), and VEGFR2 (G) mRNA in wound granulation tissue from WT mice treated with Veh or STZ, and from VEGFR1 $\mathrm{TK}^{-1-}$ mice treated with STZ, at days 0,3 , 5 , and 7. Data are expressed as the means \pm SEM. $n=12$ mice per group (A); $n=5$ to 6 mice per group (B); $n=4$ to 6 mice per group (D-G). ${ }^{*} P<0.05$ versus vehicle-treated WT mice; ${ }^{\dagger} P<0.05$ versus STZ-treated WT mice. Scale bars $=50 \mu \mathrm{m}$ (C). GAPDH, glyceraldehyde-3phosphate dehydrogenase. vehicle-treated nondiabetic WT mice, particularly during the early phase. We next generated skin wounds in STZ-treated VEGFR1 $\mathrm{TK}^{-/-}$mice to examine the role of endogenous VEGFR1 signaling in diabetic wound closure. Wound healing in STZ-induced diabetic VEGFR1 $\mathrm{TK}^{-1-}$ mice was much slower than that in STZ-induced diabetic WT mice. These results suggest that delayed wound healing in STZinduced diabetic animals is mediated through VEGFR1 signaling. We also evaluated the wound closure by histological examination (Supplemental Figure S2A). Histological analysis of the wounds revealed that the length of epithelial tongue in STZ-treated WT mice at day 3 was shorter than that in nondiabetic mice, and that in STZtreated VEGFR1 $\mathrm{TK}^{-/-}$mice was further decreased in comparison with that in STZ-treated WT mice (Supplemental Figure S2B). The distance of epithelial tips in STZ-treated WT mice was longer than that in nondiabetic mice, and that in STZ-treated VEGFR1 $\mathrm{TK}^{-1-}$ mice was greater than that in STZ-treated WT mice (Supplemental Figure S2C). The area of the granulation tissues in STZ-treated WT mice was reduced compared with that in nondiabetic mice, and this was further attenuated in STZ-treated VEGFR1 $\mathrm{TK}^{-1-}$ mice (Supplemental Figure S2D).

Because angiogenesis is necessary for wound healing, we also examined angiogenesis in the wound granulation tissue in terms of CD31 (an endothelial cell marker) expression. Real-time RT-PCR analysis revealed significantly lower CD31 mRNA levels in STZ-treated WT mice than in vehicle-treated WT mice at days 3, 5, and 7 (Figure 1B). The levels of CD31 mRNA in STZ-treated VEGFR1 $\mathrm{TK}^{-1-}$ mice at days 3 and 5 were lower than those in STZ-treated WT mice.

Immunofluorescence analysis using an anti-CD31 antibody confirmed that the expression of CD31 in the wound granulation tissue in STZ-treated VEGFR1 $\mathrm{TK}^{-1-}$ mice was lower than that in STZ-treated WT mice at day 7 
(Figure 1C). Microvessel density in the wound granulation tissue of STZ-treated VEGFR1 $\mathrm{TK}^{-1-}$ mice was significantly lower than in that of STZ-treated WT mice at day 7 (Figure 1D). To further confirm that VEGFR1 signaling is important for diabetic wound-associated angiogenesis, microvascular density was determined using an antibody against MECA32, a specific marker for ECs of blood vessels. Similar results were obtained with MECA32 antibody (Supplemental Figure S3).

We next measured the expression of VEGF-A, a potent proangiogenic growth factor, in the wound granulation tissue. The levels of VEGF-A mRNA in vehicle-treated WT mice at days 3,5, and 7 were significantly higher than those at day 0 (Figure 1E). VEGF-A mRNA levels in STZinduced diabetic WT mice during wound healing were lower than those in nondiabetic mice, and VEGF-A mRNA levels in STZ-induced diabetic VEGFR1 $\mathrm{TK}^{-1-}$ mice were lower than those in STZ-induced diabetic WT mice. A similar trend in VEGFR1 mRNA levels was observed in the wound granulation tissue of STZ-treated WT mice (Figure 1F). The levels of mRNA expression of extracellular domain in VEGFR1 in nondiabetic mice were increased during surgical wound healing. By contrast, no significant changes were observed in both STZ-induced diabetic WT mice and STZ-induced diabetic VEGFR1 $\mathrm{TK}^{-1-}$ mice, and there were no significant differences in VEGFR1 extracellular domain mRNA levels between the two groups.

The levels of VEGFR2 mRNA in nondiabetic wounds increased during the course of wound healing, whereas those in STZ-induced diabetic wounds in WT mice and VEGFR1 $\mathrm{TK}^{-1-}$ mice were down-regulated (Figure 1G). There was no significant difference in VEGFR2 mRNA levels between STZ-treated WT mice and STZ-treated VEGFR1 $\mathrm{TK}^{-/-}$mice.

\section{VEGFR1 Signaling Accelerates Lymphangiogenesis in STZ-Induced Diabetic Wounds}

Both angiogenesis and lymphangiogenesis are necessary for wound healing. ${ }^{5,6}$ Thus, we next evaluated lymphangiogenesis in the wound granulation tissue.

Immunohistochemical analysis with an antibody specific for the lymphatic-specific marker Lyve-1 revealed fewer
A

Lyve-1/DAPI
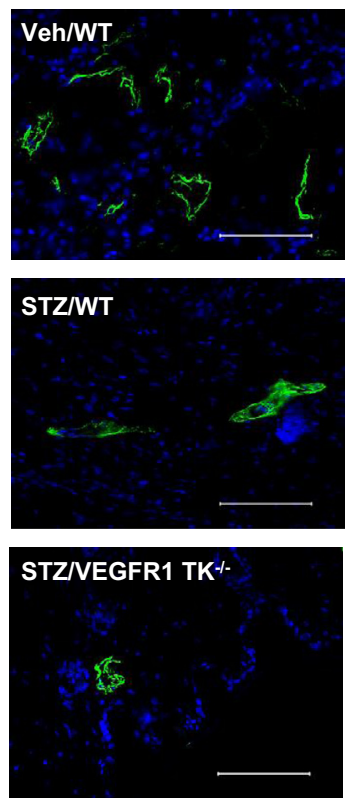

B

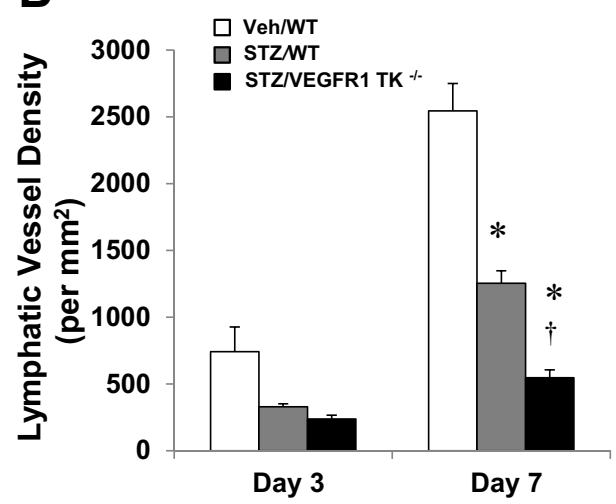

D

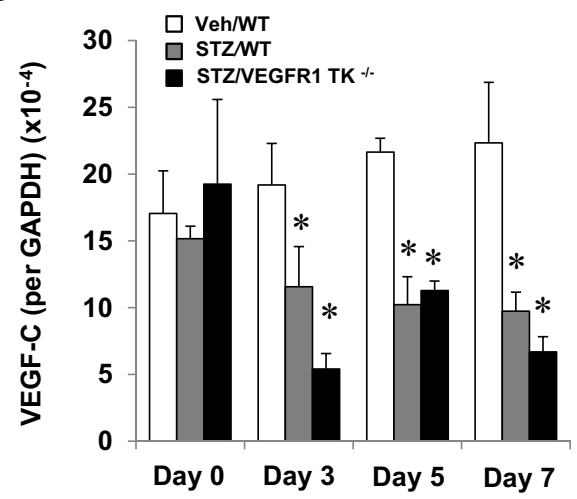

C

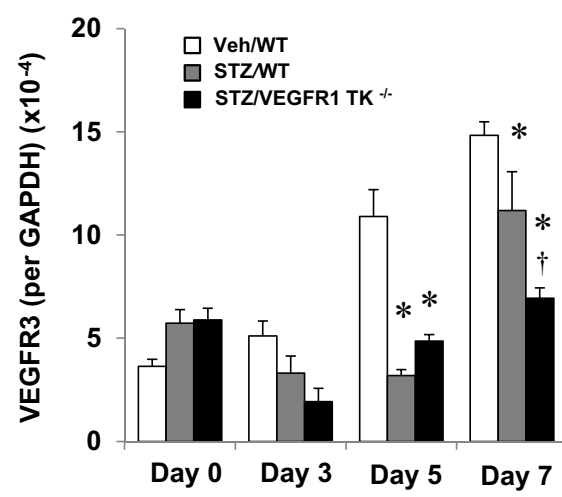

E

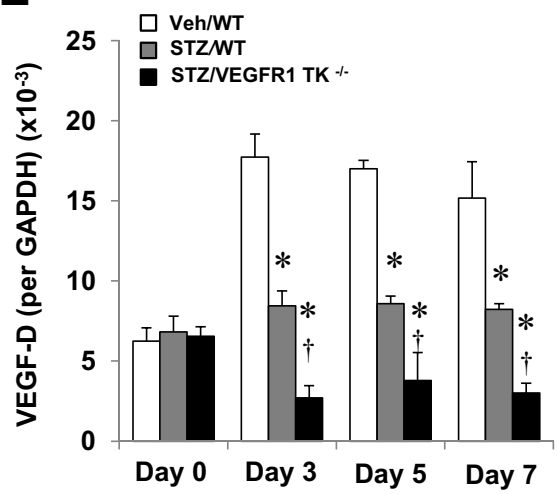

Figure 2 Vascular endothelial growth factor receptor type 1 (VEGFR1) signaling facilitates lymphangiogenesis in streptozotocin (STZ)-induced diabetic wounds. A: Representative images showing immunofluorescence staining for lymphatic vessel endothelial hyaluronan receptor (Lyve-1) (green) in the wound granulation tissue of wild-type (WT) mice treated with vehicle (Veh) or STZ, and of VEGFR1 tyrosine kinase (TK) ${ }^{-1-}$ mice treated with STZ, at day 7 after wounding. Cell nuclei were stained with DAPI (blue). B: Lymphatic vessel density in the wound granulation tissue from WT mice treated with vehicle (Veh) or STZ, and from VEGFR1 TK ${ }^{-1-}$ mice treated with STZ, at days 3 and 7. C-E: Changes in the expression of VEGFR3 (C), VEGF-C (D), and VEGF-D (E) mRNA in the wound granulation tissue. Data are expressed as the means \pm SEM. $n=4$ to 6 mice per group $(\mathbf{B}) ; n=5$ to 6 mice per group $(\mathbf{C}-\mathbf{E})$. ${ }^{\star} P<0.05$ versus vehicletreated WT mice; ${ }^{\dagger} P<0.05$ versus STZ-treated WT mice. Scale bar $=50 \mu \mathrm{m}(\mathbf{A})$. 
Lyve-1-positive lymphatic structures in STZ-induced diabetic WT mice than in nondiabetic WT mice (Figure 2A). Notably, the expression of Lyve-1 in STZ-induced diabetic VEGFR1 $\mathrm{TK}^{-1-}$ mice was lower than that in STZ-induced diabetic WT mice. In addition, quantitative analysis of lymphatic vessel density confirmed that wound-induced lymphangiogenesis in STZ-induced diabetic VEGFR1 $\mathrm{TK}^{-/-}$mice at day 7 was significantly lower than that in STZ-induced diabetic WT mice (Figure 2B). To further determine whether VEGFR1 signaling is important for diabetic wound-associated lymphangiogenesis, lymph vessel density was determined using an antibody against podoplanin, a specific marker for lymphatic vessels. Similar results were obtained when podoplanin antibody was used (Supplemental Figure S4).

Real-time RT-PCR analysis also revealed significantly lower levels of VEGFR3, VEGF-C, and VEGF-D mRNA expression in STZ-induced diabetic WT mice than in nondiabetic WT mice at day 7 (Figure 2, C-E). The levels of VEGFR3 and VEGF-D mRNA expression in STZ-induced diabetic VEGFR1 $\mathrm{TK}^{-/-}$mice were lower than those in STZ-induced diabetic WT mice. However, there were no significant differences among the groups in terms of the levels of VEGF-C mRNA in the wound granulation tissue.
These results suggest that VEGFR1 signaling accelerates lymphangiogenesis in the wound granulation tissue of STZinduced diabetic mice by up-regulating prolymphangiogenic factors.

Recruitment of VEGFR1/F4/80 Double-Positive Cells to the Wound Granulation Tissue in STZ-Treated VEGFR1 $\mathrm{TK}^{-/-}$Mice Is Suppressed

Because wound macrophages play an important role in wound healing and wound-induced angiogenesis/ lymphangiogenesis, we examined the number of macrophages in the wound granulation tissue. The levels of F4/80 mRNA expression in vehicle-treated WT mice increased after surgical wounding (Supplemental Figure S5). By contrast, the expression of F4/80 mRNA in STZ-treated WT mice was down-regulated compared with that in vehicle-treated WT mice, and F4/80 expression in STZtreated VEGFR1 $\mathrm{TK}^{-1-}$ mice at day 7 was lower than that in STZ-treated WT mice.

Immunofluorescence analysis with an antibody specific for the macrophage marker $\mathrm{F} 4 / 80$ was also performed (Figure 3A). There were few F4/80-positive cells in the back skin of nondiabetic and diabetic mice at day 0 (data not
A

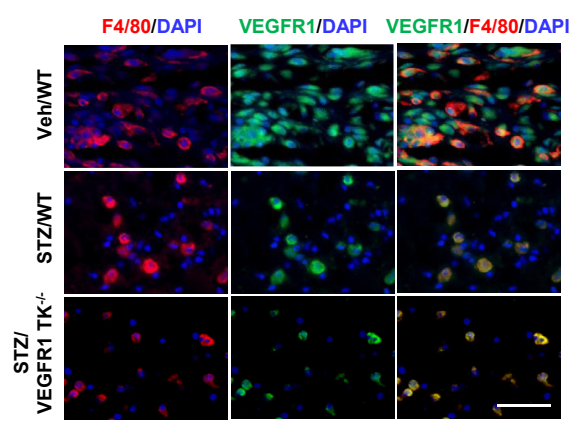

D

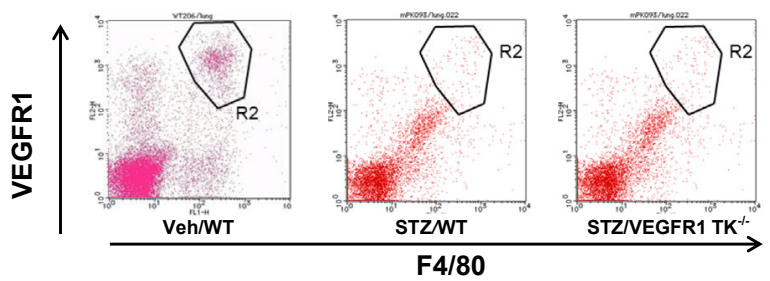

B
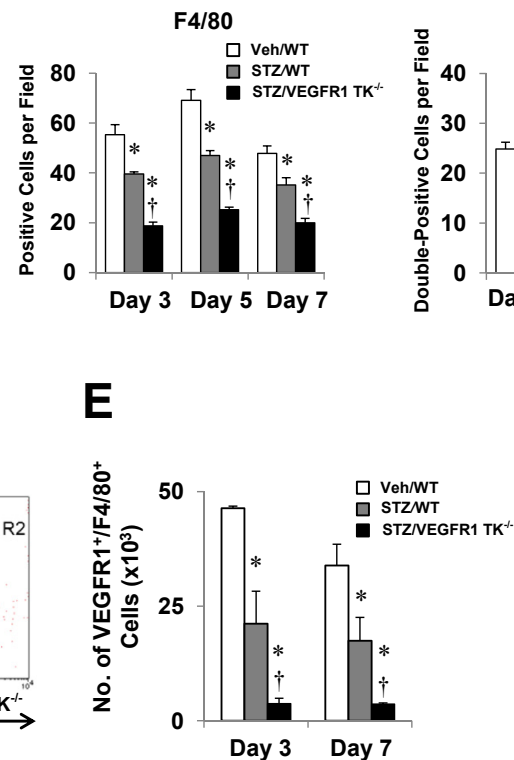

C

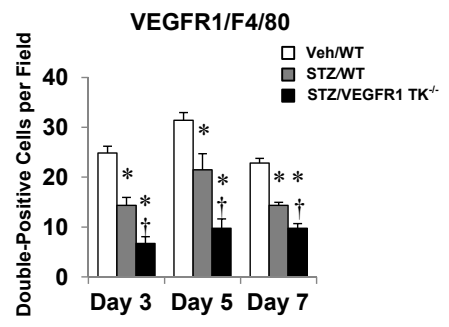

$\mathbf{F}$

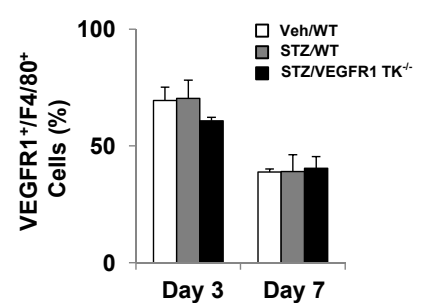

Figure 3 Vascular endothelial growth factor receptor type 1 (VEGFR1) signaling induces VEGFR1 ${ }^{+} / F 4 / 80^{+}$macrophages to invade the wound granulation tissue of streptozotocin (STZ)-induced diabetic mice. A: Representative images showing immunofluorescence staining for F4/80 (red) and VEGFR1 (green) in the wound granulation tissue from wild-type (WT) mice treated with vehicle (Veh) or STZ, and of VEGFR1 tyrosine kinase (TK) ${ }^{-/-}$mice treated with STZ, at day 3 after wounding. Cell nuclei were stained with DAPI (blue). Double-positive cells are yellow. B: Changes in the number of F4/80-positive cells recruited to wound granulation tissue. C: Total number of F4/80-VEGFR1 double-positive cells in granulation tissue from WT mice treated with vehicle or STZ, and from VEGFR1 TK ${ }^{-1-}$ mice treated with STZ. D: Representative flow cytometry plots for VEGFR1 ${ }^{+} / F 4 / 80^{+}$cells in granulation tissue from WT mice treated with vehicle or STZ, and of VEGFR1 TK ${ }^{-/-}$mice treated with STZ, at day 3 after wounding. E: The number of VEGFR1 ${ }^{+} / F 4 / 80^{+}$cells in granulation tissue as assessed by flow cytometric analysis. F: The percentages of VEGFR1 ${ }^{+} / F 4 / 80^{+}$cells in granulation tissue from WT mice treated with vehicle or STZ, and of VEGFR1 TK ${ }^{-1-}$ mice treated with STZ. Data are expressed as the means \pm SEM. $n=5$ to 6 mice per group $(\mathbf{B}$ and $\mathbf{C}) ; n=4$ to 6 mice per group $(\mathbf{E}$ and $\mathbf{F})$. ${ }^{\star} P<0.05$ versus vehicletreated WT mice; ${ }^{\dagger} P<0.05$ versus STZ-treated WT mice. Scale bar $=50 \mu \mathrm{m}(\mathbf{A})$. 
shown). The number of F4/80-positve cells in the wound granulation tissue of vehicle-treated WT mice peaked at day 5 after surgical wounding and then decreased by day 7 (Figure 3B).

The number of F4/80-positive cells in STZ-treated WT mice after surgical wounding was lower than that in vehicletreated WT mice, and the number of F4/80-positive cells in STZ-treated VEGFR1 $\mathrm{TK}^{-1-}$ mice was lower than that in STZ-treated WT mice (Figure 3B).

Because VEGFR1-expressing cells are recruited to damaged tissues, ${ }^{22,25}$ and VEGFR 1 is expressed not only by ECs but also macrophages, ${ }^{18}$ we also performed doubleimmunofluorescence staining for VEGFR1 and F4/80 to examine cell-specific expression of VEGFR1 in wound granulation tissue (Figure 3A). The results showed that the VEGFR1-positive cells were F4/80 positive, suggesting that VEGFR1 is expressed by recruited macrophages. The number of VEGFR1-F4/80 double-positive cells in the STZinduced diabetic wounds of WT mice was lower than that in the wounds of nondiabetic mice, and the number in the wounds of STZ-induced diabetic VEGFR1 $\mathrm{TK}^{-1-}$ mice was lower than that in the wounds of STZ-induced diabetic WT mice (Figure 3C). Collectively, these results suggest that VEGFR1 signaling mediates recruitment of VEGFR1expressing macrophages to diabetic wounds.

To further confirm that VEGFR1-expressing macrophages contribute to diabetic wound repair, we determined the numbers of macrophages in the wound granulation tissue by means of flow cytometry (Figure 3D). Flow cytometry analysis revealed that the numbers of VEGFR $1^{+} /$ $\mathrm{F} 4 / 80^{+}$cells in the wound granulation tissue from nondiabetic WT mice at days 3 and 7 were greater than those in STZ-treated WT mice (Figure 3E). STZ-treated VEGFR1 $\mathrm{TK}^{-1-}$ mice displayed fewer cells compared with STZtreated WT mice. These results suggest that recruitment of VEGFR1 macrophages in the wound granulation tissue appears to be dependent on VEGFR1 signaling. Treatment of mice with STZ impaired the accumulation of VEGFR1/ F4/80 double-positive macrophages. In addition, the percentages of VEGFR $1^{+} / \mathrm{F} 4 / 80^{+}$cells at days 3 and 7 in three groups of mice were approximately $70 \%$ and $40 \%$, respectively (Figure 3F). The results also indicate that a variety of cells expressing VEGFR1 are involved in the diabetic wound healing. In the early phase of wound healing, VEGFR1/F4/80 double-positive cells recruited into the wound granulation tissue, and in the later phase, VEGFR1positive cells other than macrophages are recruited into the wound granulation tissue.

\section{Localization of VEGFR1 Expression during Wound Healing}

Although VEGFR1 is mainly expressed by macrophages, we next performed double-immunofluorescence staining to examine whether VEGFR1 was also expressed by endothelial cells or by lymphatic endothelial cells (Supplemental
Figure S6). We found that the expression of VEGFR1 in wound granulation tissue partly colocalized with the expression of CD31 or MECA32 (Supplemental Figure S6, A and B); however, it did not colocalize with Lyve-1 or podoplanin (Supplemental Figure S6, C and D). These results suggest that newly formed lymphatic vessels in the wound granulation tissue do not express VEGFR1. Because flow cytometry analysis suggested that other types of cells than macrophages could express VEGFR1 in the wound granulation tissue, and because fibroblasts and neutrophils are required for wound repair, we performed doubleimmunofluorescence staining for VEGFR1 and desmin, a specific marker for fibroblasts, or Gr-1, a specific marker for neutrophils. VEGFR1 partly colocalized with desminpositive cells or Gr-1-positive cells at day 7 (Supplemental Figure S6, E and F), suggesting that VEGFR1-expressing cells likely include macrophages together with ECs, fibroblasts, and neutrophils.

Furthermore, to examine whether VEGFR1 expression is localized not only in the wound granulation tissue but also in the epidermis and vasculature, we observed the entire skin wounds (Supplemental Figure S7). In the skin tissue section stained with VEGFR1 and F4/80, the expression of VEGFR1 was demonstrated in the granulation tissue and the neodermis. In addition, VEGFR1-positive cells in the epidermis did not colocalize with F4/80 expression. This suggested that VEGFR1 is expressed by keratinocytes.

\section{VEGFR1 Signaling in BM-Derived Cells Is Essential for Wound Healing, Angiogenesis, and Lymphangiogenesis}

Our data indicate macrophages are the major source of VEGFR1 expression; however, it is suggested that VEGFR1 is expressed on macrophages, as well as on ECs. To further address whether VEGFR1 signaling in macrophages plays a critical role in surgical diabetic wound healing, we generated BM chimeras in which WT mice were transplanted with BM cells from GFP + WT mice (GFP + WT BM chimeric mice) or GFP + VEGFR1 $\mathrm{TK}^{-/-}$mice (GFP + VEGFR1 $\mathrm{TK}^{-1-}$ BM chimeric mice). Thereafter, diabetes mellitus was induced by administration of STZ to chimera mice. The wound closure in GFP + WT BM chimeric mice treated with STZ was accelerated compared with GFP + VEGFR1 $\mathrm{TK}^{-1-}$ BM chimeric mice treated with STZ (Supplemental Figure S8A). In addition, compared with GFP + VEGFR1 $\mathrm{TK}^{-1-} \mathrm{BM}$ chimeric mice treated with STZ, angiogenesis and lymphangiogenesis were promoted in GFP + WT BM chimeric mice treated with STZ (Supplemental Figure S8B). These results suggested that VEGFR1 signaling in BM cells prevents the wounds from impairment in diabetic surgical wound healing, angiogenesis, and lymphangiogenesis.

To investigate whether recruited BM-derived cells are macrophage-linage cells into the wound granulation tissue, ${ }^{22,26}$ we examined the expression of F4/80 into the 
A

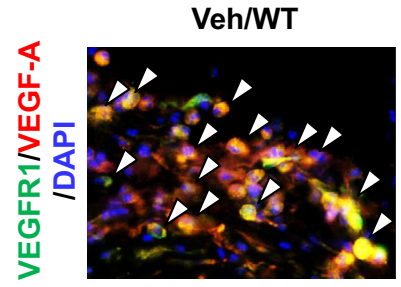

B

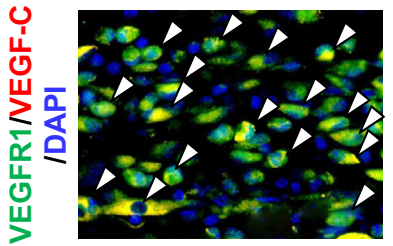

C

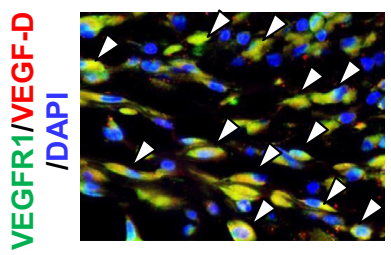

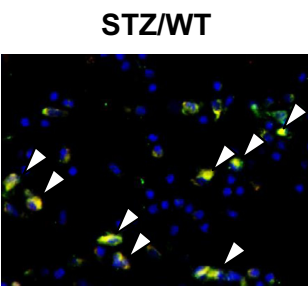
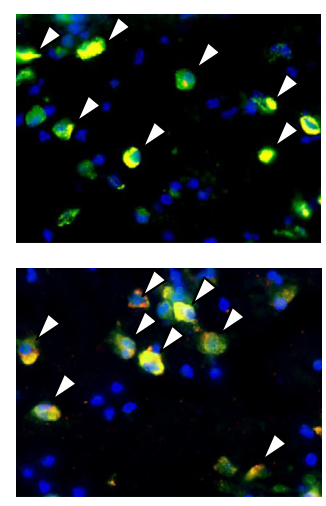

E

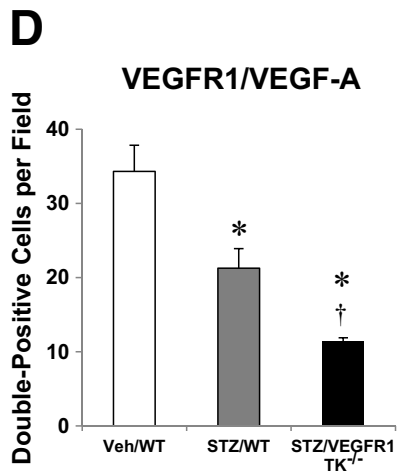

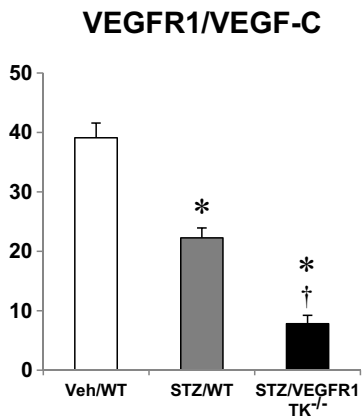

STZ/VEGFR1 TK-/-
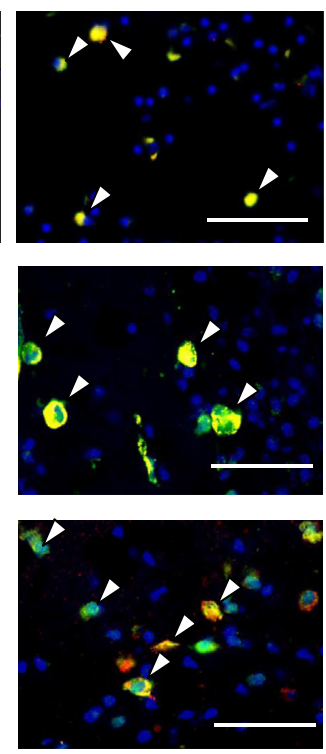

$\mathbf{F}$

VEGFR1/VEGF-D

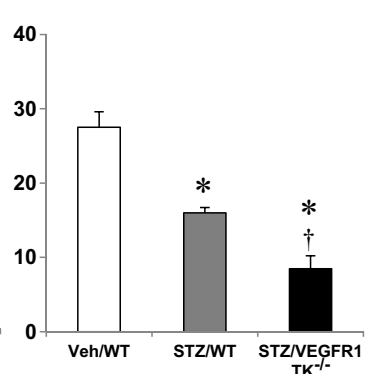

Figure 4 Recruitment of vascular endothelial growth factor receptor type 1 (VEGFR1)-positive cells expressing VEGF-A, VEGF-C, or VEGF-D to wound granulation tissue of streptozotocin (STZ)induced diabetic is dependent on VEGFR1 signaling. A: Representative double-immunofluorescence staining of VEGFR1 (green) and VEGF-A (red) in wound granulation tissue from WT mice treated with vehicle or STZ, and from VEGFR1 tyrosine kinase $(\mathrm{TK})^{-/-}$mice treated with STZ, at day 3 after wounding. Cell nuclei were stained with DAPI (blue). Double-positive cells are yellow (arrowheads). B and C: Representative images showing double-immunofluorescence staining for VEGFR1 (green) and VEGF-C (red) or VEGF-D (red) in wound granulation tissue from WT mice treated with vehicle or STZ, and from VEGFR1 $\mathrm{TK}^{-/-}$mice treated with STZ, at day 7. Cell nuclei were stained with DAPI (blue). Double-positive cells are yellow (arrowheads). D-F: Number of VEGFR1 and VEGF-A (D), VEGF-C (E), or VEGF-D (F) double-positive cells in granulation tissue from WT mice treated with vehicle or STZ, and from VEGFR1 TK ${ }^{-1-}$ mice treated with STZ. Data are expressed as the means \pm SEM. $n=5$ to 6 mice per group $(\mathbf{D}-\mathbf{F})$. ${ }^{*} P<0.05$ versus vehicle-treated WT mice; ${ }^{\dagger} P<0.05$ versus STZtreated WT mice. Scale bar $=50 \mu \mathrm{m}(\mathbf{A}-\mathbf{C})$.

wound granulation tissue of mice reconstituted with $\mathrm{GFP}^{+}$ BM cells. Double-immunofluorescence staining revealed that F4/80-positive cells in the wound granulation tissue at day 3 were positive for GFP (Supplemental Figure S8C). The numbers of $\mathrm{GFP}^{+} \mathrm{F} 4 / 80$ double-positive cells in $\mathrm{GFP}^{+}$VEGFR1 $\mathrm{TK}^{-1-}$ BM chimeric mice treated with STZ at days 3 and 7 were lower than those in $\mathrm{GFP}^{+} \mathrm{WT} \mathrm{BM}$ chimeric mice treated with STZ (Supplemental Figure S8D). These results suggested that VEGFR1 signaling in BMderived macrophages plays an important role in STZinduced diabetic wound healing and angiogenesis.

\section{Recruitment of VEGFR1-Positive Macrophages} Expressing VEGF-A, VEGF-C, or VEGF-D to STZ-Induced Wounds Is Dependent on VEGFR1 Signaling

To examine whether VEGFR1-positive macrophages promote wound-related angiogenesis via VEGF-A secretion, we performed double-immunofluorescence staining for VEGFR1 and VEGF-A (Figure 4A). The number of VEGFR1/VEGF-A double-positive cells in the wounds of STZ-treated WT mice at day 3 was lower than that in the wounds of vehicle-treated WT mice (Figure 4D).
In addition, the number of VEGFR1/VEGF-A doublepositive cells in the wounds of STZ-treated VEGFR1 $\mathrm{TK}^{-1-}$ mice was lower than that in the wounds of STZ-treated WT mice. These results suggest that VEGFR1 signaling restores impaired angiogenesis in STZ-induced diabetic wound granulation tissue by inducing VEGF-A secretion by VEGFR1-expressing macrophages.

We also examined whether VEGFR1-positive macrophages promote wound-associated lymphangiogenesis via the secretion of VEGF-C and VEGF-D. To this end, we performed double-immunofluorescence staining for VEGFR1 and VEGF-C or VEGF-D (Figure 4, B and C). The number of VEGFR1/VEGF-C double-positive cells in STZ-treated WT mice at days 3 and 7 was lower than that in vehicletreated WT mice (Figure 4E). In addition, the number of VEGFR1/VEGF-C cells in STZ-treated VEGFR1 $\mathrm{TK}^{-/-}$ mice was lower than that in STZ-treated WT mice. The same was true for VEGFR1/VEGF-D double-positive cells (Figure 4, C and F). These results suggest that VEGFR1 signaling promotes STZ-induced diabetic wound-associated lymphangiogenesis via secretion of VEGF-C and VEGF-D by VEGFR1-expressing macrophages in the wound granulation tissue. 

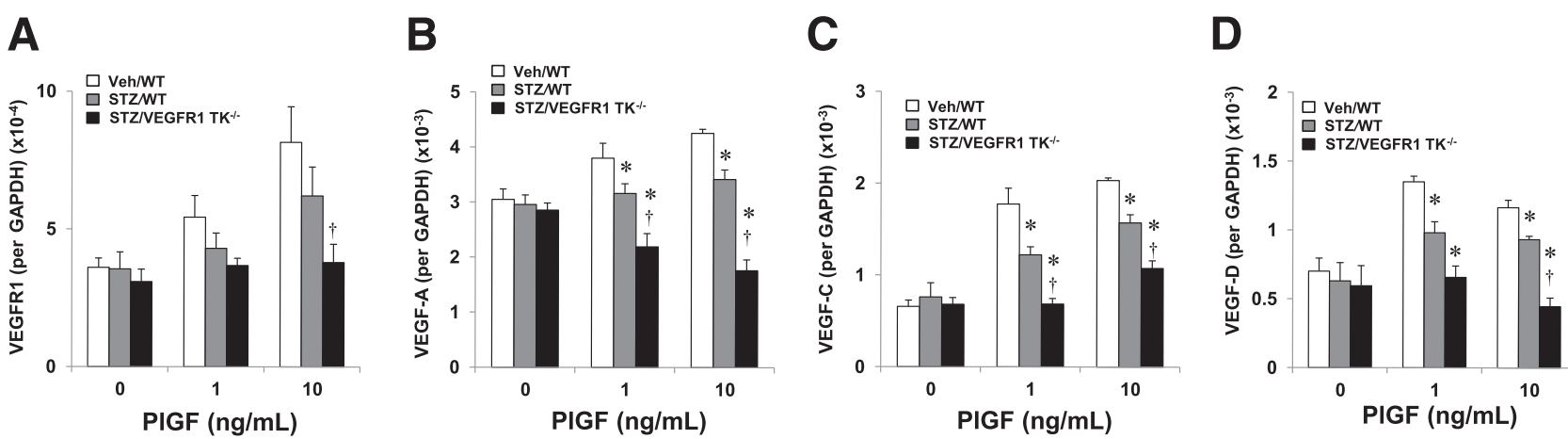

Figure 5 Effect of placenta growth factor (PIGF) on the expression of vascular endothelial growth factor receptor type 1 (VEGFR1), VEGF-A, VEGF-C, and VEGF-D in peritoneal thioglycollate-induced macrophages. Macrophages isolated from wild-type (WT) mice treated with vehicle (Veh) or streptozotocin (STZ), and from VEGFR1 tyrosine kinase (TK) ${ }^{-/}$mice treated with STZ, were stimulated with PIGF (a specific agonist for VEGFR1), and the levels of VEGFR1 (A), VEGF-A (B), VEGF-C (C), and VEGF-D (D) were determined 6 hours later. Real-time quantitative RT-PCR assays were performed to assess mRNA expression. Data are expressed as the means \pm SEM of three separate experiments. ${ }^{*} P<0.05$ versus Veh-treated WT macrophages; ${ }^{\dagger} P<0.05$ versus STZ-treated WT macrophages.

VEGFR1 Signaling Is Critical for Up-Regulation of Proangiogenic/Lymphangiogenic Growth Factors in Isolated STZ-Induced Diabetic Macrophages

To explore whether VEGFR1 signaling regulates the profile of macrophages during the healing of STZ-induced diabetic wounds, we examined the in vitro effects of PlGF (a VEGFR1 agonist) on macrophages isolated from the peritoneal cavities of mice (Figure 5).

Peritoneal macrophages isolated from vehicle- or STZtreated WT mice and then stimulated with PIGF showed a dose-dependent increase in VEGFR1 expression; however, there was no increase in VEGFR1 expression by macrophages isolated from STZ-treated VEGFR1 $\mathrm{TK}^{-1-}$ mice (Figure 5A). We next asked whether VEGF-A production by STZ-induced diabetic macrophages was dependent on VEGFR1 signaling. We found that PlGF-induced VEGF-A expression was up-regulated in nondiabetic WT macrophages, but not in STZ-induced diabetic WT or VEGFR1 $\mathrm{TK}^{-1-}$ macrophages (Figure 5B). Thus, diabetes impairs the up-regulation of VEGF-A expression by macrophages in response to PlGF.

These results suggest that VEGFR1 signaling plays a role in down-regulating the expression of VEGF-A by STZinduced WT macrophages in the wound granulation tissue. Thus, VEGFR1 signaling is important for angiogenesis during the process of STZ-induced diabetic wound healing.

The expression of VEGF-C mRNA in response to PIGF also increased in nondiabetic WT macrophages (Figure 5C). In addition, there was a moderate increase in VEGF-C mRNA levels in STZ-treated WT macrophages, but not in VEGFR1 $\mathrm{TK}^{-1-}$ macrophages. The same was true for VEGF-D expression by macrophages treated with PlGF (Figure 5D).

These results suggest that VEGFR1 signaling plays a role in down-regulating the expression of VEGF-C and VEGF-D by STZ-induced WT macrophages. Therefore, VEGFR1 signaling plays an important role in lymphangiogenesis by inducing VEGF-C and VEGF-D expression in STZ-induced diabetic WT macrophages during the process of wound healing.

Chemokine Expression during the Process of STZ-Induced Diabetic Wound Granulation Tissue Formation

Chemokine signaling is essential for the recruitment of macrophages to a wound. Therefore, we used RT-PCR to examine the expression of several chemokines that are chemotactic for macrophages (and that of their receptors, including CCL2 and CCR2) in wound granulation tissue (Supplemental Figure S9).

The levels of CCL2 mRNA in the wound granulation tissue of nondiabetic WT mice increased 3 days after surgical wounding. However, the levels of CCL2 mRNA also increased in STZ-induced diabetic WT mice and in VEGFR1 $\mathrm{TK}^{-1-}$ mice. Indeed, there were no significant differences in CCL2 levels among the three groups. The mRNA levels of CCR2 (the receptor for CCL2) were higher in nondiabetic and STZ-induced diabetic mice than in the respective controls on day 3; however, no significant change was noted in STZinduced diabetic VEGFR $1 \mathrm{TK}^{-1-}$ mice. In addition, the levels of CCR2 mRNA in STZ-induced diabetic wound granulation tissue from WT and VEGFR1 $\mathrm{TK}^{-1-}$ mice were lower than those in tissue from nondiabetic mice.

These results suggest that VEGFR1 signaling plays a role in CCR2-mediated recruitment of macrophages to STZinduced diabetic wounds.

\section{VEGFR1 Signaling Does Not Affect the Proliferation of} Lymphatic Endothelial Cells

We examined whether VEGFR1 signaling increases lymphangiogenesis by directly inducing the proliferation of lymphatic endothelial cells (Supplemental Figure S10). Lymphatic endothelial cells proliferated in response to VEGF-C but not in response to PlGF, suggesting that VEGFR1 signaling indirectly mediates lymphangiogenesis during the process of wound healing. 
A
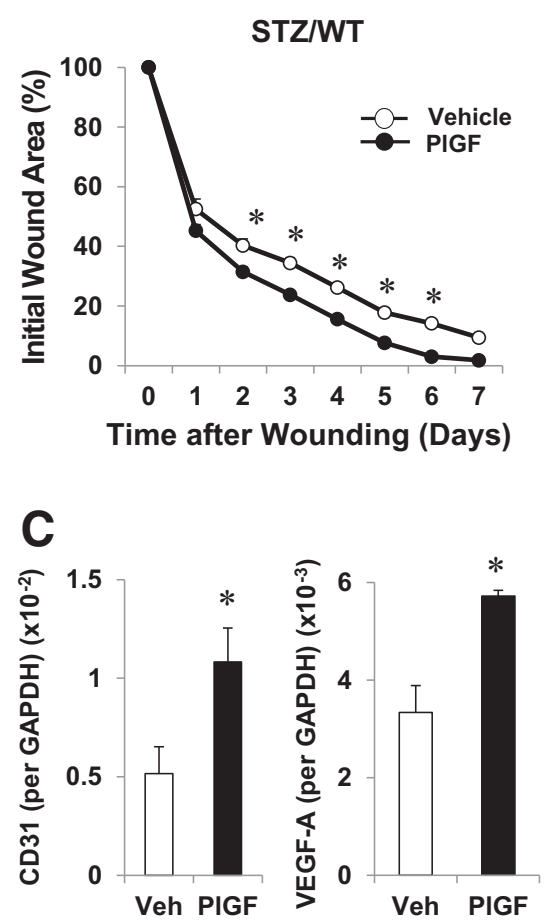

D

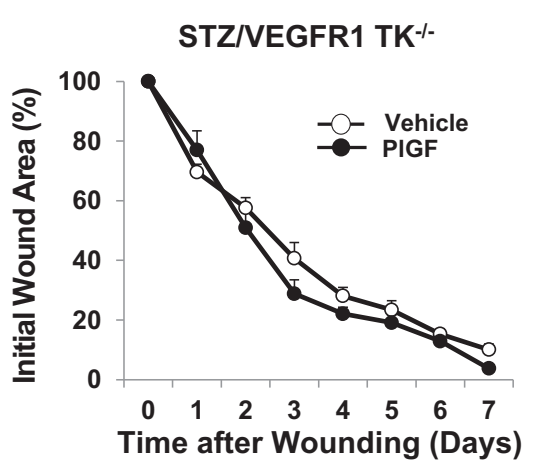

\section{B}
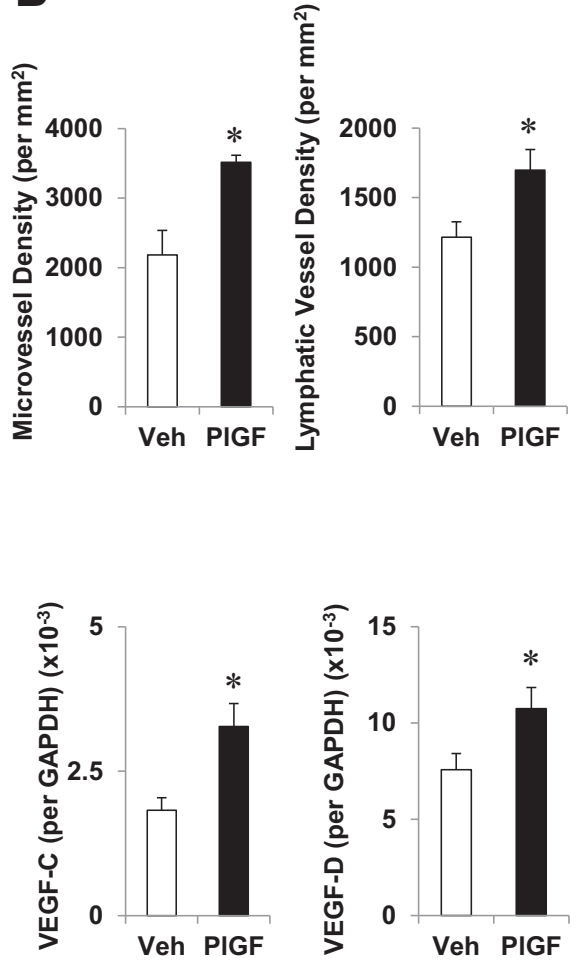

\section{E}

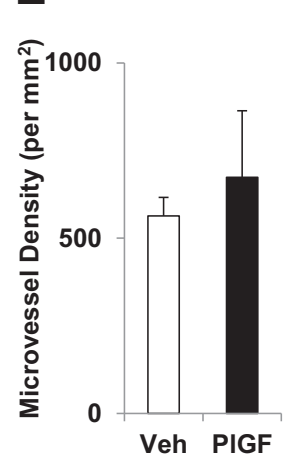

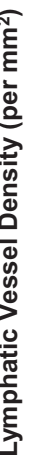

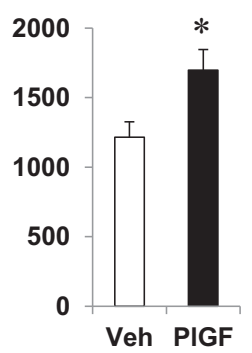

Figure 6 Placenta growth factor (PIGF) restores streptozotocin (STZ)-induced diabetic wound healing in wild-type (WT) mice, but not in VEGFR1 tyrosine kinase (TK $)^{-/-}$mice. A: Closure of wounds on the backs of STZ-treated WT mice treated with PIGF or vehicle (Veh). PIGF was continuously administered via a s.c. pump, as described in Materials and Methods. B: Density of microvessels or lymphatic vessels in the wound granulation tissue of STZ-induced WT mice treated with PIGF or Veh at day 7 after wounding. Granulation tissue was stained for CD31 or lymphatic vessel endothelial hyaluronan receptor (Lyve-1), and microvessel density or lymphatic vessel density was expressed as the number of microvessels or lymphatic vessels per $\mathrm{mm}^{2}$. C: The levels of CD31, VEGF-A, VEGF-C, and VEGF-D mRNA in the wound granulation tissue from STZ-induced WT mice treated with PIGF or Veh at day 7 were determined by real-time PCR. D: Closure of wounds on the backs of STZ-treated VEGFR1 $\mathrm{TK}^{-1-}$ mice treated with PIGF or Veh. PIGF was continuously administered via a s.c. pump, as described in Materials and Methods. E: Density of microvessels or lymphatic vessels in the wound granulation

PIGF Accelerates STZ-Induced Diabetic Wound Healing in WT Mice, but Not in VEGFR1 $\mathrm{TK}^{-/-}$Mice

To confirm the functional role of VEGFR1 signaling in STZ-induced diabetic wound healing, STZ-induced diabetic mice were treated with PIGF, and the levels of PIGF in the wound granulation tissue were measured (Supplemental Figure S11). The results showed that the levels of PIGF mRNA in STZ-treated WT mice were lower than those in vehicle-treated WT mice, and that the levels in STZ-treated VEGFR $1 \mathrm{TK}^{-1-}$ mice were lower than those in STZ-treated WT mice (Supplemental Figure S6). Next, we examined the effect of PlGF on wound healing (Figure 6). Treatment of STZ-induced diabetic WT mice with PIGF facilitated wound closure and enhanced angiogenesis and lymphangiogenesis when compared with vehicle treatment (Figure 6, A and B). tissue of STZ-induced VEGFR1 $\mathrm{TK}^{-1-}$ mice treated with PIGF or Veh at day 7. Granulation tissue was stained for CD31 or Lyve-1, and microvessel density or lymphatic vessel density in the wound granulation tissue was calculated as the number of microvessels or lymphatic vessels per $\mathrm{mm}^{2}$. Data are expressed as the means \pm SEM. $n=6$ mice per group (A); $n=4$ mice per group (B-E). ${ }^{*} P<0.05$ versus Veh-treated mice.

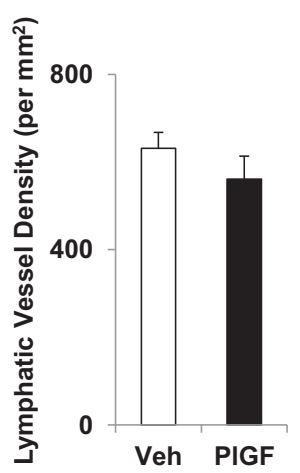

Compared with vehicle treatment, PIGF increased the expression of CD31 and VEGF-A mRNA in the STZ-induced diabetic wounds of WT mice at day 7. Similarly, PIGF increased the expression of VEGF-C and VEGF-D mRNA in the STZ-induced diabetic wounds of WT mice at day 7 (Figure 6C). By contrast, PIGF failed to accelerate wound healing and angiogenesis/lymphangiogenesis in STZ-treated VEGFR1 $\mathrm{TK}^{--}$mice (Figure 6, D and E).

\section{Enhanced Expression of Genes Associated with M1 Macrophages and Attenuated Expression of Genes Associated with M2 Macrophages in STZ-Induced Diabetic Wound Granulation Tissue}

Recent evidence suggests that wound macrophages can be categorized into two groups: classically activated 
A

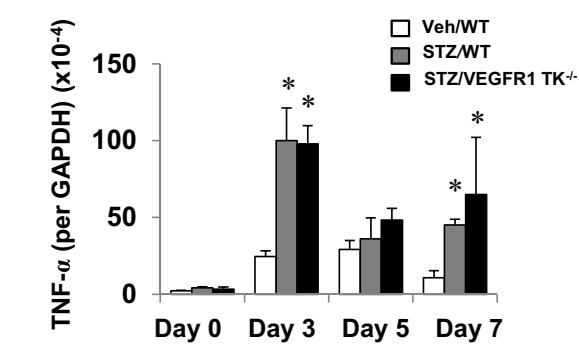

C

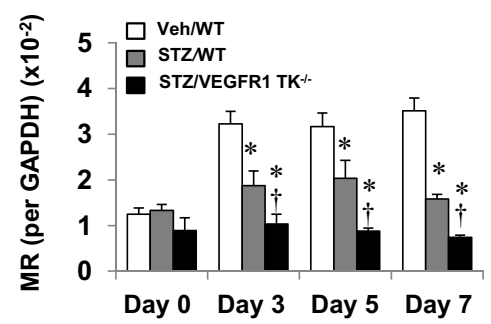

E
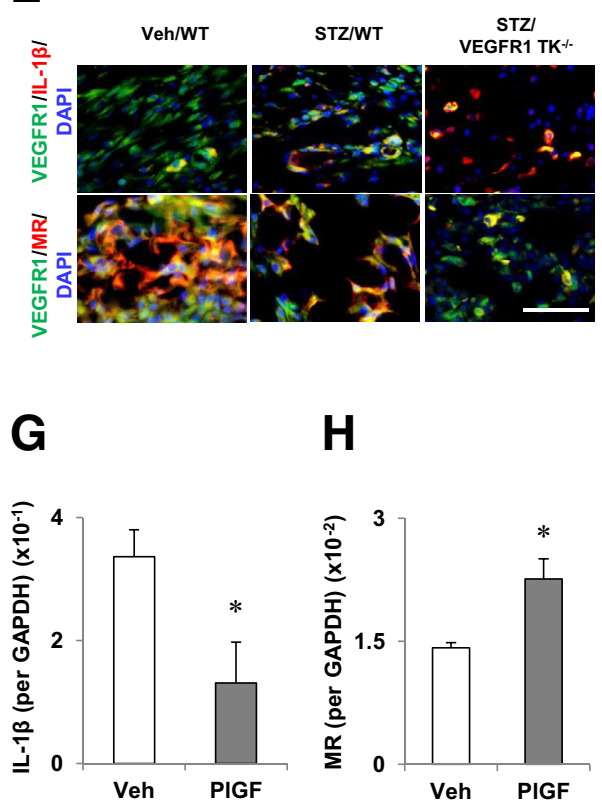

B

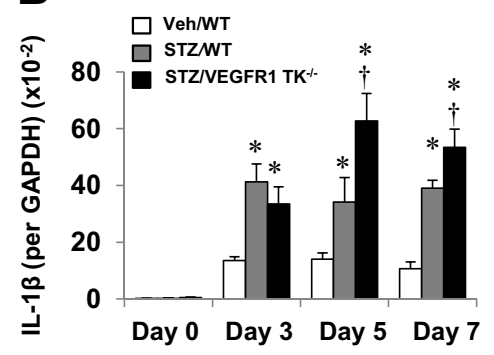

D

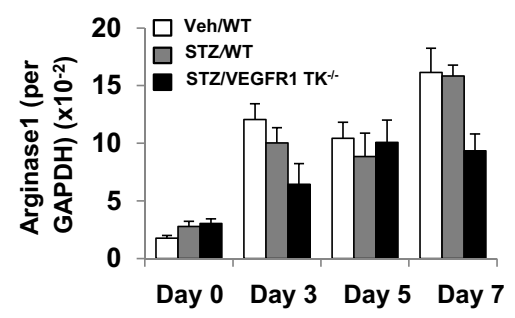

$\mathbf{F}$

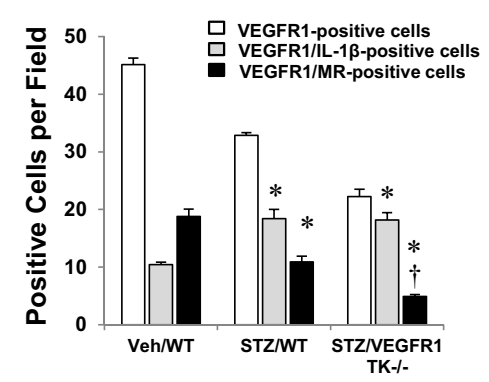

I

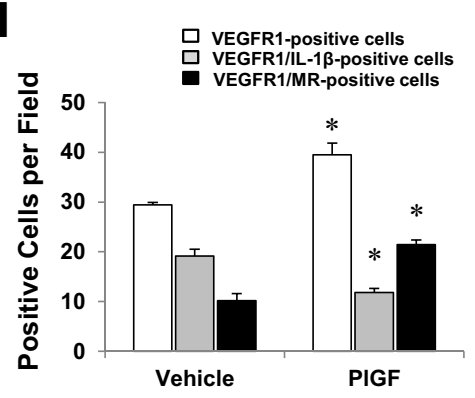

Figure 7 Increased numbers of M1 macrophages and decreased numbers of M2 macrophages in the wound granulation tissue of streptozotocin (STZ)-treated vascular endothelial growth factor receptor type 1 (VEGFR1) tyrosine kinase (TK) ${ }^{-/-}$ mice. The levels of mRNA for classic (M1) and alternative (M2) macrophage activation markers in the wound granulation tissue from wild-type (WT) mice treated with vehicle or STZ, and from VEGFR1 $\mathrm{TK}^{-1-}$ mice treated with STZ, were measured by real-time PCR. Expression of tumor necrosis factor (TNF)- $\alpha$ (A) and IL-1 $\beta$ (B) mRNA (M1 markers), and mannose receptor (MR; $\mathbf{C}$ ) and arginase 1 (D) mRNA (M2 markers). E: Dual immunostaining of granulation tissue from WT mice treated with vehicle or STZ, and from VEGFR1 $\mathrm{TK}^{-/-}$mice treated with STZ, at day 7 with antibodies against VEGFR1 (green) and IL-1 $\beta$ (red) or MR (red). F: Number of VEGFR1/ IL-1 $\beta$ or VEGFR1/MR double-positive cells in wound granulation tissue from WT mice treated with vehicle or STZ, and from VEGFR1 $\mathrm{TK}^{-/-}$mice treated with STZ, at day 7. G and $\mathbf{H}$ : Levels IL-1 $\beta$ (M1 marker) (G) and MR (M2 marker) (H) mRNA. The mRNA levels in wound granulation tissue from STZ-induced diabetic WT mice treated with PIGF or vehicle (Veh) at day 7 were determined by realtime PCR. I: Number of VEGFR1-positive and VEGFR1/IL-1 $\beta$ or VEGFR1/MR double-positive cells in wound granulation tissue from STZ-induced diabetic WT mice treated with PIGF and vehicle at day 7. Data are expressed as the means \pm SEM. $n=5$ to 6 mice per group (A-D and $\mathbf{F}$ ); $n=4$ mice per group $(\mathbf{G}-\mathbf{I})$. ${ }^{*} P<0.05$ versus Vehtreated mice; ${ }^{\dagger} P<0.05$ versus STZ-treated WT mice. Scale bar $=50 \mu \mathrm{m}(\mathbf{E})$. macrophages (proinflammatory M1 phenotype) and alternatively activated macrophages (tissue-repairing M2 phenotype). ${ }^{36}$ To characterize the infiltrating macrophage population in the wounds, we next performed quantitative RT-PCR to examine macrophage markers. We found that the expression of tumor necrosis factor- $\alpha$ and IL- $1 \beta$ mRNA (both markers of M1 macrophages) was higher in the wound granulation tissue of STZ-treated WT mice than in that of controls (Figure 7, A and B). The levels of IL-1 $\beta$ in wound granulation tissue from VEGFR $1 \mathrm{TK}^{-1-}$ mice at days 5 and 7 were even higher. By contrast, expression of markers for M2 macrophages, including MR (CD206), was lower in wound granulation tissue from STZ-treated WT mice than in tissue from controls
(Figure $7 \mathrm{C}$ ). The levels of MR mRNA in wound granulation tissue from STZ-treated VEGFR1 $\mathrm{TK}^{-1-}$ mice were lower than those in STZ-treated WT mice. There were no significant differences in the levels of arginase 1 (another M2 marker) among the three groups (Figure 7D).

Collectively, these results suggest that STZ-induced diabetic VEGFR1 $\mathrm{TK}^{-1-}$ mice exhibit an imbalance in the type of macrophage present in STZ-induced diabetic wound granulation tissue; this imbalance favors proinflammatory macrophages. Thus, VEGFR1 signaling down-regulates expression of the M1 marker, IL-1 $\beta$, and up-regulates expression of the M2 marker, MR, during STZ-induced diabetic wound healing. 
Increased Numbers of M1 Macrophages and Decreased Numbers of M2 Macrophages in STZ-Induced Diabetic Wound Granulation Tissue from VEGFR1 TK ${ }^{-/-}$Mice

We next performed double immunostaining for VEGFR1 and IL- $1 \beta$ or MR to examine dynamic changes in the activation of VEGFR1-positive macrophages in the wound granulation tissue at day 7 (Figure 7E). A high number of VEGFR1-positive cells present in the wound granulation tissue from STZ-treated WT mice expressed IL-1 $\beta$ at day 7 , whereas only a low number expressed MR (Figure 7E). Quantitative analysis revealed that the number of VEGFR1positive cells expressing IL-1 $\beta$ was higher, and the number of MR-expressing VEGFR1 macrophages was lower, in STZ-treated WT mice than in vehicle-treated mice (Figure 7F). Furthermore, the number of VEGFR1/IL-1 $\beta$ double-positive cells in wound granulation tissue from STZtreated VEGFR1 $\mathrm{TK}^{-/-}$was not significantly different from that in STZ-treated WT mice; however, the percentage of VEGFR1/IL-1 $\beta$ double-positive cells within the VEGFR1positive cell population in STZ-treated VEGFR1 $\mathrm{TK}^{-/-}$ mice was higher than that within the VEGFR1-positive cell population in STZ-treated WT mice (82\% versus $56 \%$; $P<0.05)$. In addition, the number of VEGFR1/MR doublepositive cells in STZ-treated WT mice was reduced by $42 \%$ compared with that in vehicle-treated WT mice. The number of VEGFR1/MR-positive cells in STZ-treated VEGFR1 $\mathrm{TK}^{-1-}$ mice was even lower (a 55\% decrease). Taken together, these results indicate that VEGFR1 signaling plays a role in regulating M1-to-M2 polarization of VEGFR1positive macrophages in STZ-induced diabetic wounds. These results also suggest that VEGFR1-dependent production of IL-1 $\beta$, which is produced by M1 macrophages, may suppress STZ-induced diabetic wound healing.

VEGFR1 Signaling Restores M1-to-M2 Plasticity during the Process of Wound Healing in STZ-Induced Diabetic Mice

To further confirm that VEGFR1 signaling regulates macrophage polarization during the healing of STZ-induced diabetic wounds, we examined the M1 and M2 phenotype in the wound granulation tissue and in VEGFR1-positive cells after treatment of mice with PIGF.

Compared with vehicle treatment, PIGF treatment reduced the levels of IL-1 $\beta$ mRNA, and increased the levels of MR mRNA, in wound granulation tissue from STZtreated WT mice at day 7 (Figure 7, G and H).

Immunostaining revealed that the number of VEGFR1positve cells in the wound granulation tissue of PlGF-treated STZ-induced diabetic WT mice at day 7 was higher than that in vehicle-treated mice (Figure 7I). In addition, double immunostaining for VEGFR1 and IL-1 $\beta$ or MR revealed that the number of VEGFR1/IL-1 $\beta$ double-positive cells in PlGF-treated STZ-treated WT mice was lower than that in vehicle-treated STZ-induced diabetic mice (Figure 7I). PIGF increased the number of MR-expressing VEGFR1 macrophages in the wound granulation tissue of STZ-treated WT mice to a greater extent than vehicle (Figure 7I).

These results suggest that VEGFR1 signaling downregulates the M1 marker, IL-1 $\beta$, and up-regulates the M2 marker, MR, in STZ-induced diabetic macrophages, and that VEGFR1 signaling plays a critical role in M1-to-M2 polarization of macrophages during the healing of STZinduced diabetic wounds.

\section{Neutralizing IL-1 $\beta$ Accelerates Wound Closure and Angiogenesis in STZ-Treated VEGFR1 TK ${ }^{-/-}$Mice}

Because increased IL-1 $\beta$ production from VEGFR1expressing macrophages was associated with delayed wound healing in STZ-induced diabetic WT and VEGFR1 $\mathrm{TK}^{-1-}$ mice, we next examined whether blocking IL-1 $\beta$ would normalize impaired wound healing in STZ-induced diabetic mice. Compared with vehicle, the continuous administration of a neutralizing antibody against IL- $1 \beta$ to STZ-treated VEGFR1 $\mathrm{TK}^{-1-}$ mice promoted wound closure (Figure 8A) and increased angiogenesis and lymphangiogenesis (as measured by microvessel density) (Figure $8 \mathrm{~B}$ ). There were no significant differences in glucose levels measured on days 0 and 7 (data not shown). In addition, the neutralizing antibody against IL-1 $\beta$ increased the expression of CD31, Lyve-1, and VEGFR3 mRNA in the wound granulation tissue of STZtreated VEGFR1 $\mathrm{TK}^{-1-}$ mice (Supplemental Table S1). Compared with vehicle, treatment of STZ-induced diabetic VEGFR $1 \mathrm{TK}^{-1-}$ mice with the IL-1 $\beta$ neutralizing antibody also led to increased expression of mRNA for the proangiogenic growth factor, VEGF-A, and for the prolymphangiogenic factors, VEGF-C and VEGF-D (Supplemental Table S1). Treatment with the IL-1 $\beta$ neutralizing antibody also increased the levels of Lyve-1 and VEGFR3 mRNA in STZ-induced diabetic VEGFR1 $\mathrm{TK}^{-/-}$mice.

Finally, we examined the effect of the anti-IL-1 $\beta$ antibody on the phenotype of the macrophages present in the wound granulation tissue of STZ-treated VEGFR1 $\mathrm{TK}^{-/-}$ mice. Compared with vehicle treatment, treatment with the IL-1 $\beta$ neutralizing antibody reduced the levels of IL-1 $\beta$ mRNA and increased the levels of MR mRNA (Figure 8C). Furthermore, the number of VEGFR1-positive macrophages expressing IL-1 $\beta$ was lower, and that of VEGFR1-positive macrophages expressing MR was higher, after neutralizing antibody treatment than after vehicle treatment (Figure 8D).

Taken together, these results suggest that inhibiting IL- $\beta$ in STZ-induced diabetic VEGFR1 $\mathrm{TK}^{-1-}$ mice normalizes the switch from M1 to M2 macrophages during the course of wound healing.

\section{Discussion}

Macrophages play a critical role in diabetic wound healing. ${ }^{11}$ A previous study shows that the number of 


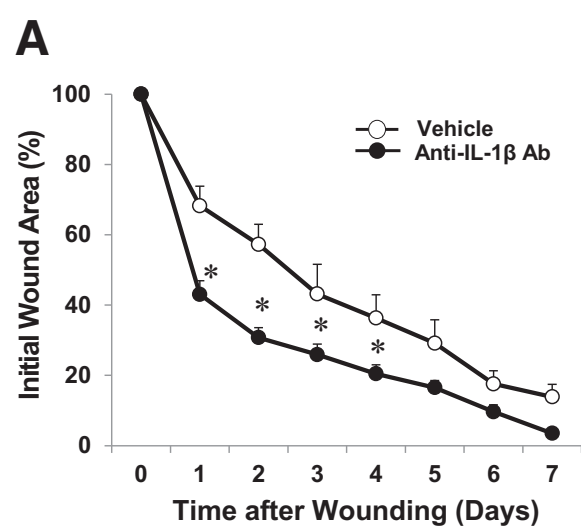

B
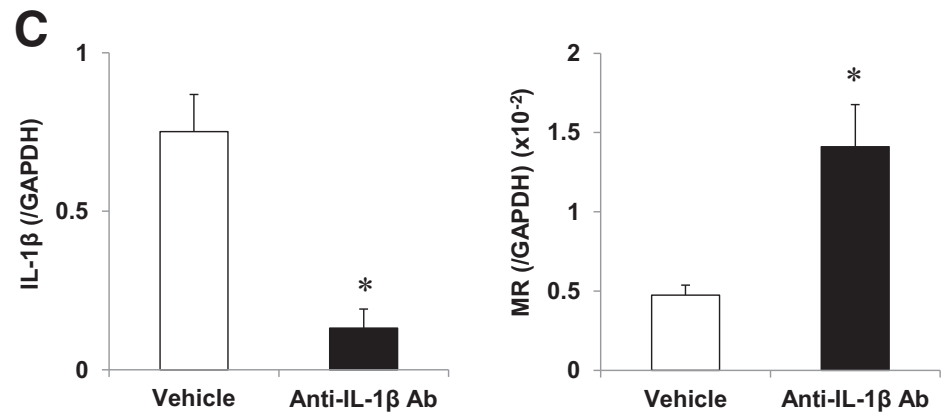

D

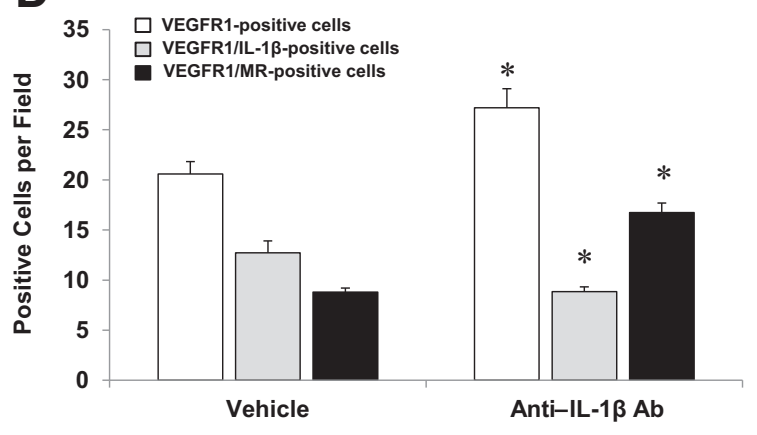

Figure 8 Effect of an IL-1 $\beta$ neutralizing antibody on wound healing in streptozotocin (STZ)-induced diabetic vascular endothelial growth factor receptor type 1 (VEGFR1) tyrosine kinase (TK $)^{-/-}$mice. A: Closure of wounds on the backs of STZ-treated VEGFR1 TK$^{-/-}$mice treated with an IL-1 $\beta$ neutralizing antibody or control IgG [vehicle (Veh)]. The IL-1 $\beta$ neutralizing antibody was continuously administered via a s.c. pump, as described in Materials and Methods. B: Density of microvessels or lymphatic microvessels in the wound granulation tissue of STZ-induced VEGFR1 $\mathrm{TK}^{-1-}$ mice treated with an IL-1 $\beta$ neutralizing antibody or control IgG (Veh) at day 7 . Granulation tissue was stained for CD31 or Lyve-1, and microvessel or lymphatic microvessel density in the wound granulation tissue was calculated as the number of microvessels or lymphatic microvessels per $\mathrm{mm}^{2}$. Cell nuclei were stained with DAPI (blue). C: Levels of IL-1 $\beta$ and mannose receptor (MR) mRNA in wound granulation tissue from STZ-induced VEGFR1 $\mathrm{TK}^{-/-}$mice treated with an IL-1 $\beta$ neutralizing antibody or control IgG (Veh) at day 7 were measured by real-time PCR. D: Numbers of VEGFR1positive and VEGFR1/IL-1 $\beta$ or VEGFR1/MR double-positive cells in wound granulation tissue from STZ-induced VEGFR1 $\mathrm{TK}^{-/-}$mice treated with an IL-1 $\beta$ neutralizing antibody or vehicle (control IgG) at day 7. Data are expressed as the means \pm SEM. $n=4$ mice per group $(\mathbf{A}, \mathbf{B}$, and $\mathbf{D}) ; n=5$ to 6 mice per group (C). ${ }^{*} P<0.05$ versus Veh-treated mice. LVD, lymphatic microvessel density; MVD, microvessel density. proinflammatory macrophages is increased in STZ-induced diabetic wound tissues, leading to delayed wound healing. ${ }^{30}$ However, it is unclear how macrophages maintain proinflammatory responses and impair the process of wound healing. Previously, we reported that VEGFR1 signaling facilitates tissue repair by recruiting VEGFR1-positive macrophages into injured tissues. ${ }^{22,25,26}$ We also showed that VEGFR1 signaling promotes nondiabetic wound healing via recruitment of macrophages. ${ }^{27}$ Herein, we showed that endogenous VEGFR1 signaling accelerates STZ-induced diabetic wound healing by inhibiting IL-1 $\beta$ secretion by VEGFR1-positive macrophages recruited to the wound granulation tissue. Although the underlying mechanism by which VEGFR1 alters in the proinflammatory phenotype remains to be determined, attenuation of macrophage proinflammatory activity may be a potential strategy for accelerating diabetic wound healing.

Delayed diabetic wound healing, along with suppressed angiogenesis and lymphangiogenesis, is associated with the down-regulation of proangiogenic growth factors (eg, VEGF-A) and prolymphangiogenic growth factors (eg, VEGF-C and VEGF-D). ${ }^{2}$ Previous reports show that VEGF-A treatment promotes wound healing in genetically diabetic mice ( $\mathrm{db} / \mathrm{db}$ mice) by increasing angiogenesis. ${ }^{37,38}$ Herein, we found that VEGFR1 signaling increases VEGF-A production by VEGFR1-expressing macrophages recruited to the wound granulation tissue, thereby promoting wound healing and angiogenesis. Indeed, PlGF augmented wound healing and angiogenesis in STZ-induced diabetic WT mice, but not in diabetic VEGFR1 $\mathrm{TK}^{-/-}$mice, suggesting that impaired angiogenesis during the healing of STZ-induced diabetic wounds appears to be mediated by suppressed VEGFR1-induced recruitment of VEGF-A-expressing macrophages.

In addition, promotion of lymphangiogenesis by VEGF-C accelerates diabetic wound healing in genetically diabetic db/db mice. ${ }^{39}$ The present study also demonstrated that VEGFR1 signaling facilitates lymphangiogenesis and 
increases the expression of VEGF-C and VEGF-D by VEGFR1-positive macrophages recruited to the granulation tissue in STZ-induced diabetic mice. The expression of VEGF-C and VEGF-D in isolated STZ-treated macrophages in response to PlGF was dependent on VEGFR1 signaling, suggesting that VEGFR1 signaling recruits VEGFR1expressing macrophages into STZ-induced wounds; these macrophages then secrete VEGF-C and VEGF-D to promote lymphangiogenesis. Therefore, impaired STZ-induced diabetic wound-induced lymphangiogenesis is likely caused by inactivation of VEGFR1 signaling in macrophages.

Delayed wound healing and suppressed angiogenesis/ lymphangiogenesis in STZ-treated mice correlated with reduced recruitment of macrophages to the diabetic wound. Because VEGF-A recruits VEGFR1-expressing macrophages, ${ }^{19,40}$ attenuated expression of VEGF-A in STZinduced diabetic wounds will lead to impaired recruitment of VEGFR1-positive macrophages. We showed herein that VEGFR1 signaling promotes the recruitment of VEGFR1positive macrophages during the process of STZ-induced diabetic wound healing. These results are consistent with those published in previous studies. ${ }^{22,25,26} \mathrm{We}$ previously reported that VEGFR1 signaling promotes the recruitment of VEGFR1-expressing macrophages to repair the injured tissues, such as liver and stomach, ${ }^{2,25,26}$ and that VEGFR1 signaling mediates monocyte/macrophage infiltration to local inflammatory sites. ${ }^{19,27}$ The recruitment of peritoneal macrophages is dependent on VEGFR1 signaling. ${ }^{19} \mathrm{PlGF}$ is a strong chemoattractant for VEGFR-1-expressing monocytes, ${ }^{23,41}$ and the therapeutic activity of PIGF is mediated by accumulated macrophages. ${ }^{4}$ We found that PIGF treatment was associated with an increased number of VEGFR1positive macrophages in STZ-induced diabetic wounds. Together with the results reported herein, these findings indicate that impairment in VEGFR1 signaling is responsible for suppression of the recruitment of VEGFR1expressing macrophages into the diabetic wound granulation tissue.

Besides the impairment in macrophage recruitment through VEGF-A/VEGFR1 signaling in the process of diabetic wound repair, attenuated expression of chemokines also results in reduced recruitment of macrophages to diabetic wound granulation tissue, leading to impaired diabetic wound healing. ${ }^{42}$ The expression of CCR2 in the granulation tissue of STZ-induced diabetic mice was lower than that in nondiabetic mice, suggesting that CCR2-mediated recruitment of macrophages to the granulation tissue is crucial for wound healing. ${ }^{43}$ In addition, CCR2-mediated recruitment of VEGFR1-expressing macrophages to STZinduced diabetic wound granulation tissue was dependent on VEGFR1 signaling. We also determined other chemokines/their receptors, including CCL3, CCL5, and CCR5; however, there were no significant differences between nondiabetic and diabetic mice. ${ }^{30}$

The current studies indicate that VEGFR1 is expressed on recruited F4/80-positive cells (macrophages) into the wound granulation tissue and that VEGFR1 signaling in BMderived macrophages recruited into the granulation tissue is essential for diabetic wound healing. Although the major source of VEGFR1 expression appears to be macrophages during the process of diabetic wound healing, flow cytometry analysis reveals that other cell types than macrophages could be responsible for diabetic wound healing. Because VEGFR1 is expressed by ECs and macrophages, ${ }^{17}$ woundassociated angiogenesis would be caused by enhanced expression of VEGFR1 in ECs. Immunofluorescence analysis reveals that VEGFR1 is partially expressed by ECs in the wound granulation tissue. Nevertheless, we cannot exclude the possibility that VEGFR1 signaling contributes to diabetic wound angiogenesis by affecting EC function. Indeed, VEGFR2 expression is attenuated in STZ-induced diabetic VEGFR1 $\mathrm{TK}^{-1-}$ mice, suggesting that VEGFR1 signaling facilitates diabetic wound-related angiogenesis with up-regulation of VEGFR2 expression in ECs. VEGFR2 signaling plays a role in impaired angiogenesis and EC dysfunction during diabetic wound healing. ${ }^{44}$ In addition, the current study demonstrates that epidermal cells also express VEGFR1, which is consistent with previous results. ${ }^{45}$ This indicates that VEGFR1 signaling in keratinocytes is likely involved in diabetic wound healing. Furthermore, it is suggested that VEGFR1 is expressed on fibroblasts ${ }^{46}$ and neutrophils, ${ }^{47}$ which are key players for wound repair. The present study shows that fibroblasts and neutrophils in the wound granulation tissue express VEGFR1. Collectively, VEGFR1 is expressed on macrophages, but also at various extents in ECs, keratinocytes, fibroblasts, and neutrophils; VEGFR1 signaling in macrophages, together with ECs, keratinocytes, neutrophils, and fibroblasts, is involved in diabetic wound healing. Thus, different types of cells expressing VEGFR1 signaling participate in diabetic wound healing; however, the role of VEGFR1 signaling in each cell type in diabetic wound healing remains to be elucidated in our model.

Although macrophages play a critical role in diabetic wound healing via angiogenesis/lymphangiogenesis, the polarization of wound macrophages is critical for the healing of diabetic wounds. Diabetic wounds contain insufficient numbers of M2 macrophages. Our results showed that the number of macrophages expressing IL-1 $\beta$ (an M1 macrophage marker) was increased, and the number of macrophages expressing MR (an M2 macrophage marker) was decreased, in the wound granulation tissue in STZinduced diabetic mice, suggesting that STZ-induced diabetic wounds maintain strong M1 marker expression and weak M2 marker expression. These results are in agreement with those of previous studies. ${ }^{2,16,30}$

The present findings also indicate that VEGFR1 signaling is involved in deficient switching from an M1 to an M2 phenotype during impaired STZ-induced diabetic wound healing. The wounds of STZ-induced diabetic VEGFR1 TK ${ }^{-1-}$ mice showed greater accumulation of VEGFR1/IL-1 $\beta$ doublepositive macrophages than the wounds of STZ-induced 
diabetic WT mice. The STZ-induced diabetic wounds of VEGFR1 $\mathrm{TK}^{-1-}$ mice also contained fewer VEGFR1/MR double-positive (M2-polarized) macrophages. The administration of PIGF to STZ-treated WT mice normalized macrophage polarization. These results suggest that the increased proinflammatory/reduced prohealing phenotype of STZinduced macrophages is dependent on VEGFR1 signaling. Although the mechanisms by which VEGFR1 signaling regulates the M1-to-M2 phenotypic switch during STZ-induced diabetic wound healing remain unclear, these results suggest that VEGFR1 signaling plays a critical role in correcting the imbalance between M1 and M2 polarization in STZ-induced diabetic macrophages, which is responsible for impaired healing of diabetic wounds.

We also showed that delayed STZ-induced diabetic wound healing is associated with persistent expression of IL-1 $\beta$ by VEGFR1-positive macrophages in the granulation tissue, indicating that excessive IL-1 $\beta$ (produced by VEGFR1-positive macrophages) prevents wound healing. Previous studies revealed important roles for IL- $1 \beta$ in regulating diabetic wound healing and repair. ${ }^{15}$ Indeed, proinflammatory M1 macrophages from $\mathrm{db} / \mathrm{db}$ mice secrete IL-1 $\beta$ and are responsible for impaired diabetic wound healing ${ }^{15}$; local injection of IL-1 $\beta$ blocking antibody into the wounds of genetically diabetic $\mathrm{db} / \mathrm{db}$ mice accelerated the wound healing process without affecting blood glucose levels. Also, inhibiting IL-1 $\beta$ at the wound site in genetically diabetic mice down-regulates the proinflammatory phenotype and up-regulates the expression of prohealing factors. ${ }^{15} \mathrm{We}$ also demonstrated that the continuous administration of an IL- $1 \beta$ neutralizing antibody to STZtreated VEGFR1 $\mathrm{TK}^{-1-}$ mice facilitated wound healing and angiogenesis/lymphangiogenesis without changing blood glucose levels. In addition, treatment of STZ-treated VEGFR1 $\mathrm{TK}^{-1-}$ mice with the IL-1 $\beta$ blocking antibody down-regulated the expression of IL-1 $\beta$ and up-regulated the expression of MR by recruited VEGFR1-positive macrophages, indicating that VEGFR1 signaling plays a critical role in the repair of STZ-induced diabetic wounds by downregulating the production of proinflammatory IL- $1 \beta$ by recruited VEGFR1-positive macrophages, thereby promoting M2 polarization. Therefore, new therapeutic strategies that promote an appropriate shift in the M1-M2 balance are required to prevent impaired diabetic wound healing. It is difficult to label macrophages as M1 or M2 because VEGFR1-expressing macrophages appear to simultaneously express markers of M1 and M2 differentiation. Macrophages are a heterogeneous population and can display phenotypes ranging from anti-inflammatory to proinflammatory.

During the process of diabetic wound healing, IL-1 $\beta$ is up-regulated in diabetic macrophages in mice, ${ }^{15}$ which is consistent with our results. The mechanism by which diabetes enhances the expression of IL-1 $\beta$ in macrophages is supposed to be mediated by oxidative stress-induced activation of inflammasome, which regulates IL-1 $\beta$ production. ${ }^{48}$ In addition, hyperglycemia-induced oxidative stress in monocytes also inhibits the VEGFR1 signaling pathway, and rather activates other intrasignaling pathways, including Akt, extracellular signal-regulated kinase $1 / 2$, and $\mathrm{p} 38 .{ }^{49}$ These findings suggest that enhanced oxidative stress and suppressed VEGFR1 signaling in diabetic macrophages constitutively activates other intracellular signaling pathways than VEGFR1 signaling, leading to the production of IL- $1 \beta .^{49}$ It remains to be determined whether enhanced oxidative stress contributes to activation of transcriptional factors, including Akt, extracellular signal-regulated kinase $1 / 2$, and p38, in diabetic VEGFR1-deficient macrophages.

In summary, the present study showed that VEGFR1 signaling induces macrophages recruited to STZ-induced diabetic wound granulation tissue to switch from an M1 to an M2 phenotype, thereby promoting the healing of STZ-induced diabetic wounds. Blocking the secretion of IL-1 $\beta$ by VEGFR1-expressing macrophages accelerates STZ-induced diabetic wound healing by increasing angiogenesis and lymphangiogenesis. Therefore, a specific agonist of VEGFR1 and an inhibitor of IL- $1 \beta$ might serve as potential novel therapeutic tools to facilitate diabetic wound healing.

\section{Acknowledgments}

We thank Michiko Ogino, Kyoko Yoshikawa, and Mieko Hamano for technical assistance.

\section{Supplemental Data}

Supplemental material for this article can be found at http://dx.doi.org/10.1016/j.ajpath.2016.02.014.

\section{References}

1. Boulton AJ, Vileikyte L, Ragnarson-Tennvall G, Apelqvist J: The global burden of diabetic foot disease. Lancet 2005, 366:1719-1724

2. Wicks K, Torbica T, Mace KA: Myeloid cell dysfunction and the pathogenesis of the diabetic chronic wound. Semin Immunol 2014, 26 : 341-353

3. Eming SA, Hammerschmidt M, Krieg T, Roers A: Interrelation of immunity and tissue repair or regeneration. Semin Cell Dev Biol 2009, 20:517-527

4. Kamoshita E, Ikeda Y, Fujita M, Amano H, Oikawa A, Suzuki T, Ogawa Y, Yamashina S, Azuma S, Narumiya S, Unno N, Majima M: Recruitment of a prostaglandin E receptor subtype, EP3-expressing bone marrow cells is crucial in wound-induced angiogenesis. Am J Pathol 2006, 169:1458-1472

5. Hosono K, Suzuki T, Tamaki H, Sakagami H, Hayashi I, Narumiya S, Alitalo K, Majima M: Roles of prostaglandin E2-EP3/EP4 receptor signaling in the enhancement of lymphangiogenesis during fibroblast growth factor-2-induced granulation formation. Arterioscler Thromb Vasc Biol 2011, 31:1049-1058

6. Kurashige C, Hosono K, Matsuda H, Tsujikawa K, Okamoto H, Majima M: Roles of receptor activity-modifying protein 1 in angiogenesis and lymphangiogenesis during skin wound healing in mice. FASEB J 2014, 28:1237-1247

7. Cursiefen C, Chen L, Borges LP, Jackson D, Cao J, Radziejewski C D'Amore PA, Dana MR, Wiegand SJ, Streilein JW: VEGF-A stimulates lymphangiogenesis and hemangiogenesis in inflammatory 
neovascularization via macrophage recruitment. J Clin Invest 2004, 113:1040-1050

8. Maruyama K, Ii M, Cursiefen C, Jackson DG, Keino H, Tomita M, Van Rooijen N, Takenaka H, D'Amore PA, Stein-Streilein J, Losordo DW, Streilein JW: Inflammation-induced lymphangiogenesis in the corne arises from CD11b-positive macrophages. J Clin Invest 2005, 115:2363-2372

9. Kataru RP, Jung K, Jang C, Yang H, Schwendener RA, Baik JE, Han SH, Alitalo K, Koh GY: Critical role of CD11b+ macrophages and VEGF in inflammatory lymphangiogenesis, antigen clearance, and inflammation resolution. Blood 2009, 113:5650-5659

10. Maruyama K, Asai J, Ii M, Thorne T, Losordo DW, D’Amore PA: Decreased macrophage number and activation lead to reduced lymphatic vessel formation and contribute to impaired diabetic wound healing. Am J Pathol 2007, 170:1178-1191

11. Brancato SK, Albina JE: Wound macrophages as key regulators of repair: origin, phenotype, and function. Am J Pathol 2011, 178:19-25

12. Mirza RE, Koh TJ: Dysregulation of monocyte/macrophage phenotype in wounds of diabetic mice. Cytokine 2011, 56:256-264

13. Lucas T, Waisman A, Ranjan R, Roes J, Krieg T, Müller W, Roers A, Eming SA: Differential roles of macrophages in diverse phases of skin repair. J Immunol 2010, 184:3964-3977

14. Sica A, Mantovani A: Macrophage plasticity and polarization: in vivo veritas. J Clin Invest 2012, 122:787-795

15. Mirza RE, Fang MM, Ennis WJ, Koh TJ: Blocking interleukin-1 $\beta$ induces a healing-associated wound macrophage phenotype and improves healing in type 2 diabetes. Diabetes 2013, 62:2579-2587

16. Khanna S, Biswas S, Shang Y, Collard E, Azad A, Kauh C, Bhasker V, Gordillo GM, Sen CK, Roy S: Macrophage dysfunction impairs resolution of inflammation in the wounds of diabetic mice. PLoS One 2010, 5:e9539

17. Ferrara N, Gerber HP, LeCouter J: The biology of VEGF and its receptors. Nat Med 2003, 9:669-679

18. Shibuya M: Vascular endothelial growth factor-dependent and -independent regulation of angiogenesis. BMB Rep 2008, 41:278-286

19. Hiratsuka S, Minowa O, Kuno J, Noda T, Shibuya M: Flt-1 lacking the tyrosine kinase domain is sufficient for normal development and angiogenesis in mice. Proc Natl Acad Sci U S A 1998, 95:9349-9354

20. Carmeliet P, Moons L, Luttun A, Vincenti V, Compernolle V, De Mol M, Wu Y, Bono F, Devy L, Beck H, Scholz D, Acker T, DiPalma T, Dewerchin M, Noel A, Stalmans I, Barra A, Blacher S, VandenDriessche T, Ponten A, Eriksson U, Plate KH, Foidart JM, Schaper W, Charnock-Jones DS, Hicklin DJ, Herbert JM, Collen D, Persico MG: Synergism between vascular endothelial growth factor and placental growth factor contributes to angiogenesis and plasma extravasation in pathological conditions. Nat Med 2001, 7:575-583

21. Kaplan RN, Riba RD, Zacharoulis S, Bramley AH, Vincent L, Costa C, MacDonald DD, Jin DK, Shido K, Kerns SA, Zhu Z, Hicklin D, Wu Y, Port JL, Altorki N, Port ER, Ruggero D, Shmelkov SV, Jensen KK, Rafii S, Lyden D: VEGFR1-positive haematopoietic bone marrow progenitors initiate the pre-metastatic niche. Nature 2005, 438:820-827

22. Ohkubo H, Ito Y, Minamino T, Eshima K, Kojo K, Okizaki S, Hirata M, Shibuya M, Watanabe M, Majima M: VEGFR1-positive macrophages facilitate liver repair and sinusoidal reconstruction after hepatic ischemia/reperfusion injury. PLoS One 2014, 9: e105533

23. Clauss M, Weich H, Breier G, Knies U, Röckl W, Waltenberger J, Risau W: The vascular endothelial growth factor receptor Flt-1 mediates biological activities: implications for a functional role of placenta growth factor in monocyte activation and chemotaxis. J Biol Chem 1996, 271:17629-17634

24. Sawano A, Iwai S, Sakurai Y, Ito M, Shitara K, Nakahata T, Shibuya M: Flt-1, vascular endothelial growth factor receptor 1, is a novel cell surface marker for the lineage of monocyte-macrophages in humans. Blood 2001, 97:785-791
25. Kato T, Ito Y, Hosono K, Suzuki T, Tamaki H, Minamino T, Kato S, Sakagami H, Shibuya M, Majima M: Vascular endothelial growth factor receptor-1 signaling promotes liver repair through restoration of liver microvasculature after acetaminophen hepatotoxicity. Toxicol Sci 2011, 120:218-229

26. Sato T, Amano H, Ito Y, Eshima K, Minamino T, Ae T, Katada C, Ohno T, Hosono K, Suzuki T, Shibuya M, Koizumi W, Majima M: Vascular endothelial growth factor receptor 1 signaling facilitates gastric ulcer healing and angiogenesis through the upregulation of epidermal growth factor expression on VEGFR1+CXCR4 + cells recruited from bone marrow. J Gastroenterol 2014, 49:455-469

27. Murakami M, Zheng Y, Hirashima M, Suda T, Morita Y, Ooehara J, Ema H, Fong GH, Shibuya M: VEGFR1 tyrosine kinase signaling promotes lymphangiogenesis as well as angiogenesis indirectly via macrophage recruitment. Arterioscler Thromb Vasc Biol 2008, 28: 658-664

28. Cianfarani F, Zambruno G, Brogelli L, Sera F, Lacal PM, Pesce M, Capogrossi MC, Failla CM, Napolitano M, Odorisio T: Placenta growth factor in diabetic wound healing: altered expression and therapeutic potential. Am J Pathol 2006, 169:1167-1182

29. Oba K, Hosono K, Amano H, Okizaki S, Ito Y, Shichiri M, Majima M: Downregulation of the proangiogenic prostaglandin E receptor EP3 and reduced angiogenesis in a mouse model of diabetes mellitus. Biomed Pharmacother 2014, 68:1125-1133

30. Okizaki S, Ito Y, Hosono K, Oba K, Ohkubo H, Amano H, Shichiri M, Majima M: Suppressed recruitment of alternatively activated macrophages reduces TGF- $\beta 1$ and impairs wound healing in streptozotocininduced diabetic mice. Biomed Pharmacother 2015, 70:317-325

31. Lynch SE, Colvin RB, Antoniades HN: Growth factors in wound healing: single and synergistic effects on partial thickness porcine skin wounds. J Clin Invest 1989, 84:640-646

32. Luttun A, Tjwa M, Moons L, Wu Y, Angelillo-Scherrer A, Liao F, Nagy JA, Hooper A, Priller J, De Klerck B, Compernolle V, Daci E, Bohlen P, Dewerchin M, Herbert JM, Fava R, Matthys P, Carmeliet G, Collen D, Dvorak HF, Hicklin DJ, Carmeliet P: Revascularization of ischemic tissues by PIGF treatment, and inhibition of tumor angiogenesis, arthritis and atherosclerosis by anti-Flt1. Nat Med 2002, 8: $8831-8840$

33. Tamarat R, Silvestre JS, Le Ricousse-Roussanne S, Barateau V, Lecomte-Raclet L, Clergue M, Duriez M, Tobelem G, Lévy BI: Impairment in ischemia-induced neovascularization in diabetes: bone marrow mononuclear cell dysfunction and therapeutic potential of placenta growth factor treatment. Am J Pathol 2004, 164:457-466

34. Ohkubo H, Ito Y, Minamino T, Mishima T, Hirata M, Hosono K, Shibuya M, Yokomizo T, Shimizu T, Watanabe M, Majima M: Leukotriene B4 type-1 receptor signaling promotes liver repair after hepatic ischemia/reperfusion injury through the enhancement of macrophage recruitment. FASEB J 2013, 27:3132-3143

35. Kashiwagi S, Hosono K, Suzuki T, Takeda A, Uchinuma E, Majima M: Role of COX-2 in lymphangiogenesis and restoration of lymphatic flow in secondary lymphedema. Lab Invest 2011, 91: $1314-1325$

36. Gordon S: Alternative activation of macrophages. Nat Rev Immunol 2003, 3:23-35

37. Galiano RD, Tepper OM, Pelo CR, Bhatt KA, Callaghan M, Bastidas N, Bunting S, Steinmetz HG, Gurtner GC: Topical vascular endothelial growth factor accelerates diabetic wound healing through increased angiogenesis and by mobilizing and recruiting bone marrowderived cells. Am J Pathol 2004, 164:1935-1947

38. Goren I, Allmann N, Yogev N, Schürmann C, Linke A, Holdener M, Waisman A, Pfeilschifter J, Frank S: A transgenic mouse model of inducible macrophage depletion: effects of diphtheria toxin-driven lysozyme M-specific cell lineage ablation on wound inflammatory, angiogenic, and contractive processes. Am J Pathol 2009, 175:132-147

39. Saaristo A, Tammela T, Farkkilā A, Kärkkäinen M, Suominen E, YlaHerttuala S, Alitalo K: Vascular endothelial growth factor-C accelerates diabetic wound healing. Am J Pathol 2006, 169:1080-1087 
40. Barleon B, Sozzani S, Zhou D, Weich HA, Mantovani A, Marmé D: Migration of human monocytes in response to vascular endothelial growth factor (VEGF) is mediated via the VEGF receptor flt-1. Blood 1996, 87:3336-3343

41. Pipp F, Heil M, Issbrucker K, Ziegelhoeffer T, Martin S, van de Heuvel J, Weich H, Fernandez B, Golomb G, Carmeliet P, Schaper W, Clauss M: VEGFR-1-selective VEGF homologue PIGF is arteriogenic: evidence for a monocyte-mediated mechanism. Circ Res 2003, 92: 378-385

42. Wood S, Jayaraman V, Huelsmann EJ, Bonish B, Burgad D, Sivaramakrishnan G, Qin S, DiPietro LA, Zloza A, Zhang C, Shafikhani SH: Pro-inflammatory chemokine CCL2 (MCP-1) promotes healing in diabetic wounds by restoring the macrophage response. PLoS One 2014, 9:e91574

43. Willenborg S, Lucas T, van Loo G, Knipper JA, Krieg T, Haase I, Brachvogel B, Hammerschmidt M, Nagy A, Ferrara N, Pasparakis M, Eming SA: CCR2 recruits an inflammatory macrophage subpopulation critical for angiogenesis in tissue repair. Blood 2012, 120:613-625

44. Warren CM, Ziyad S, Briot A, Der A, Iruela-Arispe ML: A ligandindependent VEGFR2 signaling pathway limits angiogenic responses in diabetes. Sci Signal 2014, 7:ra1
45. Wilgus TA, Matthies AM, Radek KA, Dovi JV, Burns AL, Shankar R, DiPietro LA: Novel function for vascular endothelial growth factor receptor-1 on epidermal keratinocytes. Am J Pathol 2005, 167: $1257-1266$

46. Jin $\mathrm{X}$, Ge X, Zhu DL, Yan C, Chu YF, Chen WD, Liu J, Gao PJ: Expression and function of vascular endothelial growth factor receptors (Flt-1 and Flk-1) in vascular adventitial fibroblasts. J Mol Cell Cardiol 2007, 43:292-300

47. Massena S, Christoffersson G, Vågesjö E, Seignez C, Gustafsson K, Binet F, Herrera Hidalgo C, Giraud A, Lomei J, Weström S, Shibuya M, Claesson-Welsh L, Gerwins P, Welsh M, Kreuger J, Phillipson M: Identification and characterization of VEGF-Aresponsive neutrophils expressing CD49d, VEGFR1, and CXCR4 in mice and humans. Blood 2015, 126:2016-2026

48. Mirza RE, Fang MM, Weinheimer-Haus EM, Ennis WJ, Koh TJ: Sustained inflammasome activity in macrophages impairs wound healing in type 2 diabetic humans and mice. Diabetes 2014, 63: $1103-1114$

49. Tchaikovski V, Olieslagers S, Böhmer FD, Waltenberger J: Diabetes mellitus activates signal transduction pathways resulting in VEGF resistance of human monocytes. Circulation 2009, 120:150-159 